Article

\title{
On the Feasibility of Tailoring Copper-Nickel Functionally Graded Materials Fabricated through Laser Metal Deposition
}

\author{
Sreekar Karnati ${ }^{1, *(1)}$, Yunlu Zhang ${ }^{1}$, Frank F. Liou ${ }^{1}\left(\mathbb{D}\right.$ and Joseph W. Newkirk ${ }^{2}$ \\ 1 Department of Mechanical and Aerospace Engineering, Missouri University of Science and Technology, \\ Rolla, MO 65409, USA; yzdyf@mst.edu (Y.Z.); liou@mst.edu (F.F.L.) \\ 2 Department of Materials Science and Engineering, Missouri University of Science and Technology, Rolla, \\ MO 65409, USA; jnewkirk@mst.edu \\ * Correspondence: skw92@mst.edu; Tel.: +1 573-341-4603
}

Received: 28 January 2019; Accepted: 25 February 2019; Published: 3 March 2019

\begin{abstract}
In this study, pulse-width modulation of laser power was identified as a feasible means for varying the chemical gradient in copper-nickel-graded materials. Graded material deposits of $70 \mathrm{wt}$. \%. copper-30 wt. \%. nickel on $100 \mathrm{wt}$. \%. nickel and vice versa were deposited and characterized. The 70/30 copper-nickel weight ratio in the feedstock powder was achieved through blending elemental copper and $96 \mathrm{wt}$. \%. Ni-Delero-22 alloy. At the dissimilar material interface over the course of four layers, the duty cycle of power was ramped down from a high value to optimized deposition conditions. This change was theorized to influence the remelting and deposition height, and by extension, vary the chemistry gradient. X-ray Energy Dispersive Spectroscopy (EDS) analysis showed significant differences in the span and nature of chemistry gradient with varying duty cycles. These observations were also supported by the variation in microhardness values across the interface. The influence of different chemistry gradients on the tensile performance was observed through mini-tensile testing, coupled with Digital Image Correlation (DIC). The strain fields from the DIC analysis showed variations in strain for different chemistry gradients. The strength measurements from these specimens were also different for different chemistry gradients. The site of failure was observed to always occur within the copper-rich region.
\end{abstract}

Keywords: laser metal deposition; functionally graded materials; blended elemental powders; digital image correlation; miniature tensile testing; $\mathrm{X}$-ray energy dispersive spectroscopy

\section{Introduction}

Functionally graded materials (FGM), are monolithic inhomogeneous materials whose anisotropy is tailored per the designer's definition. The concept of FGMs was first proposed by material scientists investigating novel means for fabricating thermal barrier materials [1]. Spatially varying material properties or material compositions can be used to achieve such anisotropy. The design freedoms that are available through FGMs provide scope for fabricating highly efficient multifunctional parts. Theorization and fundamental research has been carried out to identify FGM systems for applications such as lightweight heat exchangers, rocket nozzles, long-life bearings, high-performance turbine blades, etc. [2-6]

Techniques such as plasma spraying [4], die compaction [7], powder metallurgy [8], slip casting [9], and additive manufacturing [10-15] have been shown to be successful in fabricating FGMs. While successful, all of the above processes, excluding additive manufacturing, possess limited scope for attaining fine resolutions in grading material composition. Also, these techniques are often 
limited in their capability for fabricating complicated geometries. Additive Manufacturing (AM) has been proven to be a versatile and competent technique for fabricating complex geometries. The layerby-layer build approach enables the feasibility of fabricating intricate and complicated shapes. Laser Metal Deposition (LMD) is an AM technique that involves blowing the feed material into the melt pool while it in a layer-by-layer fashion. The localized delivery of the feed material in LMD provides a unique opportunity for tailoring the composition within a component.

Most of the existing literature involving FGMs and AM is limited to identifying viable material systems. The choice of materials is often driven by the interest of the aerospace and automobile industries. Most of these chosen material compositions are primarily intended for production processes, such as casting, welding, rolling, machining, forming etc. and they are not customized for AM. In addition, incorporating such materials into FGMs often leads to unforeseen situations. A compatibility from a metallurgical perspective though, i.e., a phase diagram with no possible formation of intermetallic compounds, does not guarantee structural integrity post-fabrication [10]. Mostly, these FGMs are complicated, due to the issues of compatibility among the constituent elements $[10,12,13,15-18]$. In cases where the main elements of the alloys are compatible, probable incompatibility among the remaining alloying elements could potentially leave the FGM system susceptible to flaws and early failure. In FGMs, the grading of the composition is intended to for selective transitional properties. The presence of alloying materials can also limit the minimum feasible resolution that is possible during such composition grading. Control over grading is crucial, as it is theorized to aid in alleviating stress issues arising from the difference in physical properties, such as the thermal expansion coefficient, crystal structure, composition differences, etc. In LMD, the unique opportunity for varying feedstock on the fly makes it very appealing for the fabrication of FGMs. This feature can be exploited to achieve a controlled gradient within FGMs.

To create multifunctional and multi-material components using LMD, planning should be performed for geometry, composition, and, thermal history. A voxel-based path plan, where each voxel represents the position, composition, and the required process parameters to be achieved, it needs to be generated in advance [2,19]. Particularly, in order to vary the chemical composition within the part, the composition of the feedstock needs to be varied during deposition. In LMD, this is typically achieved by swapping out the powder as needed. Custom tailoring of compositions of pre-alloyed powders to meet the grading requirements is very expensive, and often requires extensive infrastructure. The feasible and economical alternative would be to incorporate blended powders into the deposition process. Premixing of powders to the required composition [20-27], or mixing powders on-line by using a multi-powder feed system [5] can be adopted to implement varying compositions. While blending powders create the possibility for creating custom combinations, it is only a viable option for making significant changes to feedstock composition. Creating blended feedstocks to produce grading at fine levels of composition is counterproductive. Also, demanding the deposition of several blended powder feedstocks to produce a required grading schema could substantially increase the volume of the graded material component.

In this study, the authors theorize that varying laser parameters could be a potential means for attaining control over grading on a finer scale. The feasibility of using pulse width modulation for manipulating laser power to achieve different chemical gradients in LMD is presented. This study was performed on copper-nickel FGMs. The influence of varying chemistry on hardness and tensile performance was also investigated.

\section{Materials and Methods}

The LMD system used in the current study consisted of a $1 \mathrm{~kW}$ fiber laser from IPG Photonics. The operating wavelength of the laser was $1064 \mathrm{~nm}$. A spot size of $2 \mathrm{~mm}$ was used during deposition. Along with it, a custom built 3-axis Computer Numerical Control (CNC) system was used for facilitating motion during deposition. A Baystate model 1200 powder feeder was used for feeding the powder during deposition. A schematic drawing of the deposition system is shown in Figure 1. 
An edge-nozzle setup was used to feed the powder into the melt pool. Argon gas was used to transport the powder, and also to shield the deposition process from oxidation. The graded material deposits were fabricated by making a pre-deposit of the first material as a thin-wall structure, followed by the deposition of the second material, also as a thin-wall structure, on top of the pre-deposit. This lead to the grading of composition across the height of the thin-wall deposit. The thin-wall structures were made to a single melt pool thickness, i.e., a nominal thickness of $2 \mathrm{~mm}$.

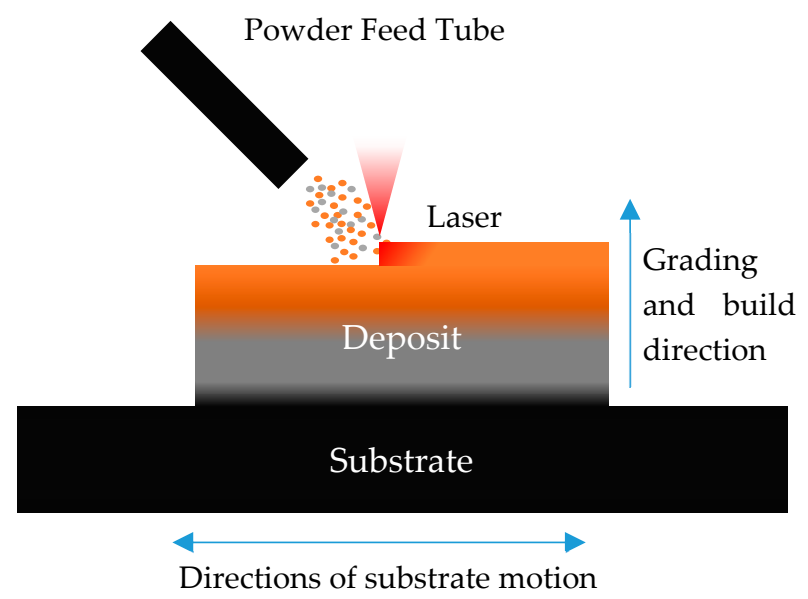

Figure 1. A schematic representation of the LMD deposition process used in the study. The gradient in the deposit illustrates the grading within the deposit; the different colors in the powder particles are used to represent blended powder feedstock.

The graded material deposits in this study were made from $-100 /+325$ mesh gas-atomized powders of elemental copper and Delero-22 alloy. The $99.9 \%$ pure copper powder was procured from Oerlikon Metco (Brea, CA, USA), and the Delero-22 powder was procured from Kennametal Stellite (Belleville, ON, Canada). Delero-22 is a nickel-silicon-boron alloy. The composition of this alloy is listed in Table 1. The boron and silicon in the alloy are expected to improve the fluidity of the material during deposition. At the current levels, silicon is completely soluble in nickel. However, the boron reacts with the nickel and produces nickel borides which improve the hardness of the material. This alloy is primarily used for thermal spraying applications; however, it exhibits excellent compatibility with LMD. The compositions of the blended feedstock powders used in the current study are shown in Table 2. These two compositions were classified as nickel-rich and copper-rich, with a relative nickel/copper weight ratio of $100 / 0$ and 30/70, respectively. Hereon, they will be referred to as $100 / 0$ and $30 / 70$.

Table 1. The composition of the Delero-22 alloy.

\begin{tabular}{rccc}
\hline Element & Silicon & Boron & Nickel \\
\hline Weight $\%$ & 2.5 & 1.4 & Balance \\
\hline
\end{tabular}

Table 2. Compositions of blended powder feedstocks used in the study.

\begin{tabular}{cccc}
\hline Powder Type & Elemental Copper (wt. \%) & Delero-22 Alloy (wt. \%) & Ni/Cu Weight Ratio \\
\hline Nickel-rich & 0 & 100 & $100 / 0$ \\
Copper-rich & 69.2 & 30.8 & $30 / 70$ \\
\hline
\end{tabular}

Graded material deposits from both nickel-rich (100/0) to copper-rich (30/70), and copper-rich $(30 / 70)$ to nickel-rich $(100 / 0)$ compositions, were performed and characterized in the current study. All depositions were carried out at a scan speed of $500 \mathrm{~mm} / \mathrm{min}$ and a powder feed rate of $1.5 \mathrm{rpm}$ (15 g/min approx.). A peak power of $1 \mathrm{~kW}$ and a duty cycle of $43 \%$ at $500 \mathrm{~Hz}$ modulation frequency 
were used for all the deposits. These parameters were chosen from a preliminary optimization study aimed at obtaining good quality single-bead deposits of Delero-22 alloy. A layer thickness of $0.15 \mathrm{~mm}$ was used for path planning. These deposits were performed on $50 \mathrm{~mm} \times 12.5 \mathrm{~mm} \times 6.35 \mathrm{~mm}$ AISI 304 stainless steel substrates. In the case of every deposit, the first material was deposited for 40 layers. This was done to ensure that no constituent elements from the substrate would interfere with the gradient under this study.

In a Pulse Width Modulation (PWM) implementation of laser power, varying the duty cycle varies the total on-time of the laser. However, the peak power is held constant. The IPG laser used in the current study has a Gaussian beam profile. So, for the same average energy input, the peak intensity could differ between Continuous Wave (CW) mode and PWM mode. During our preliminary study, a $400 \mathrm{~W}$ CW implementation produced significantly different thicknesses and deposition heights between deposits of $100 \% \mathrm{Ni}$ and $30 \% \mathrm{Ni}$. These issues were observed to decrease with increasing power. However, deposition at power levels of higher than $500 \mathrm{~W}$ leads to excess heat retention and poor deposit quality. Finding the process parameters in CW mode that could that produce similar deposition qualities for both copper and nickel rich deposits proved to be challenging. It was then hypothesized that a PWM implementation could facilitate similar deposition widths. In this, way the highest possible intensities could be achieved, and issues of heat retention could be tackled by using different duty cycles to achieve different average energy inputs. A power of $1 \mathrm{~kW}$ and a duty cycle of $43 \%$ at $500 \mathrm{~mm} / \mathrm{min}$ produced good quality deposits with similar deposition widths (Ni-rich: $2.2 \pm 0.11 \mathrm{~mm}$ and $\mathrm{Cu}$-rich: $2 \pm 0.16 \mathrm{~mm}$ ). However, the deposit heights were observed to be different. This observation leads to the thought that varying the duty cycle could be used to vary the deposit height, and by extension, vary the depth of the melt pool without producing significant differences in the width of the deposit. The width was expected to be the same, since the power/beam intensity was the same for all of the duty cycles [28]. This variation in melt pool dimensions was theorized to vary the remelting between successive layers and the volume of the material deposited in every layer. At dissimilar material interfaces, this variation in melt pool attributes is expected to achieve different grading schemes. To investigate this hypothesis, three sets of depositions with varying duty cycles were performed. The duty cycle was only varied in the initial four layers of deposition at the dissimilar material interface.

The duty cycle (D.C.) variation shown in Figure 2 was used for both 100/0 on 30/70 and 30/70 on $100 / 0$ deposits. These deposits were then sectioned and processed for various analyses. Longitudinal sections of these deposits were used for both chemistry and hardness analysis. The chemical analysis was done through standard-less X-ray Energy Dispersive Spectroscopy (EDS) on an ASPEX-PICA 1020 scanning electron microscope (SEM). The hardness testing was performed with a Duramin hardness testing machine (Struers, Cleveland, OH, USA).

Transverse cross sections of these deposits were cut, mount in Bakelite, ground, polished, and etched for optical microscopy. The etching was carried out using a mixture of $60 \mathrm{~mL} \mathrm{HNO}_{3}$ and $40 \mathrm{~mL}$ deionized (DI) water. These deposits were also sectioned for preparing miniature tensile test specimens $[22,29,30]$. The dimensions of the specimens are shown in Figure 3. These specimens were cut with a gage length along the grading direction. The specimens were tested at a constant crosshead speed of $0.6 \mathrm{~mm} / \mathrm{min}$. These tensile tests were imaged to perform a Digital Image Correlation (DIC) analysis [31]. The DIC technique was used to estimate the evolution of the strain field on the miniature tensile specimens. This was used to realize the inhomogeneous strain development in the FGMs. 

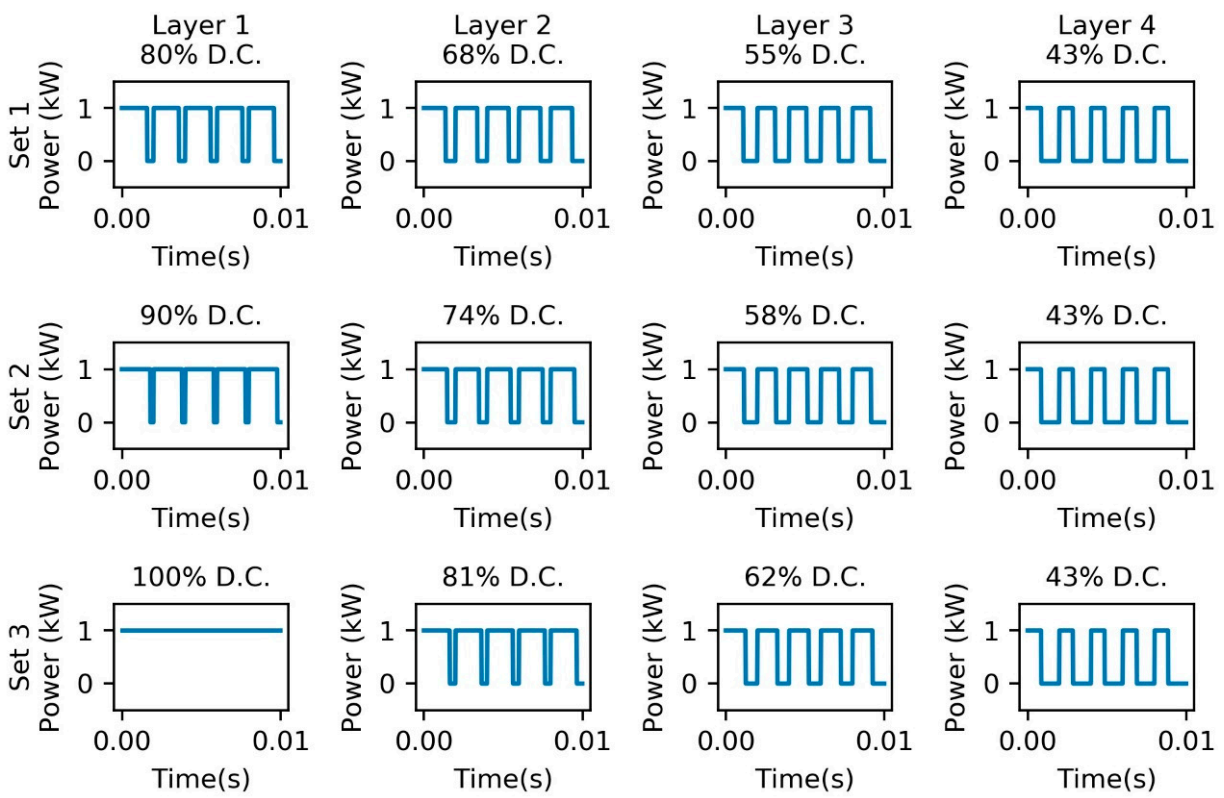

Figure 2. Power and duty cycle (D.C.) values used in the initial four layers at the dissimilar material interface while fabricating the copper-nickel FGM thin-wall deposits.

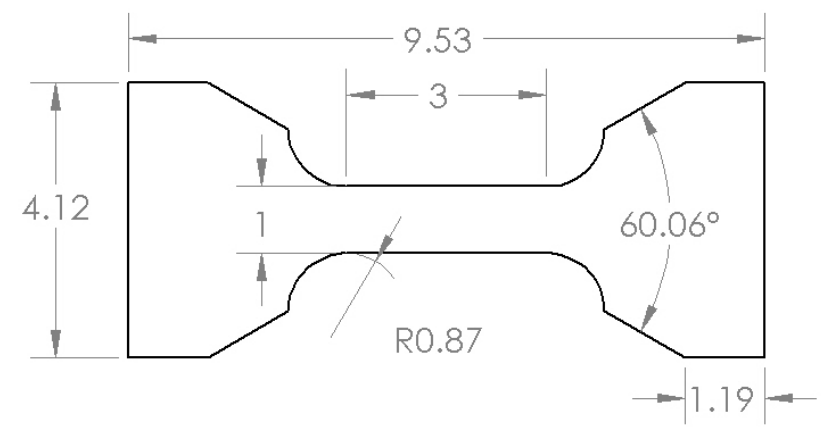

Figure 3. Dimensions of the miniature tensile test specimen; all of the dimensions are in $\mathrm{mm}$.

\section{Results and Discussion}

\subsection{Deposition of $100 / 0$ and $30 / 70$ Feedstocks}

Elemental copper has a very high thermal conductivity [32]. Also, it is highly reflective at the wavelength of the current laser [33]. This makes the melting of elemental copper extremely challenging. However, in the current study, by blending copper and Delero-22, deposition was achieved. The Delero-22 powder in the powder mixture absorbs the laser to initiate and sustain the melt pool. This melt pool is then capable of melting the elemental copper powder. Upon melting, the copper mixes with nickel, and the overall reflectivity and thermal conductivity go down substantially while making the deposited material viable for processing through LMD. However, these reflectivity issues have been observed to impact the overall capture efficiency for the blended feedstocks. The 30/70 deposits were observed to be shorter, in comparison to the 100/0 deposits. The same can be seen from the machined deposits shown in Figure 4. Similarly, the widths of the nickel-rich deposits were larger (mean \pm std. dev. $=2.2 \pm 0.11 \mathrm{~mm}$ ) than the copper-rich deposits (mean \pm std. dev. $=2 \pm 0.16 \mathrm{~mm}$ ). However, the difference in width was not as substantial as the height. 


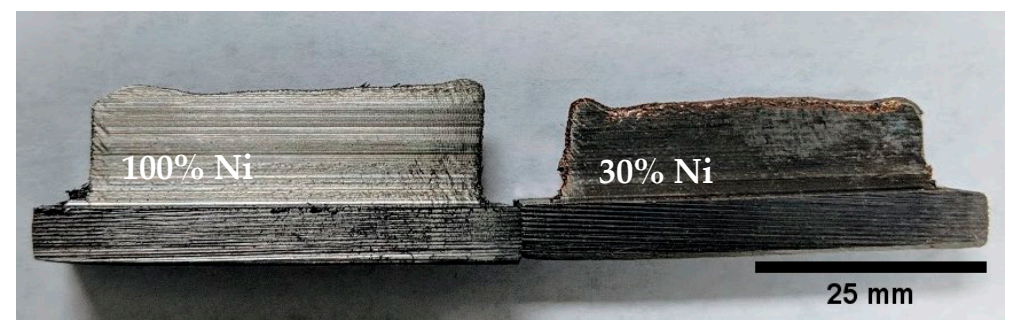

Figure 4. Machined thin-wall deposits of solely nickel-rich 100/0 (left) and copper-rich 30/70 (right) alloys, with a significant difference in overall height for the same 40 layers of deposition.

Transverse sections of these deposits were sectioned and polished for X-ray diffraction (XRD) analysis. The XRD peak patterns from the 100/0 and 30/70 deposits are shown in Figure 5. In both cases, we see strong peaks of the copper-nickel face centered cubic solid solution. The influence of adding copper can be seen from the peak shift from nickel to copper peak positions. Along with the FCC solid solution peaks, peaks corresponding to nickel boride $\left(\mathrm{Ni}_{3} \mathrm{~B}\right)$ were also observed. However, these peaks were absent in the $30 / 70$ peak pattern. Although the peaks were absent, we suspect the $\mathrm{Ni}_{3} \mathrm{~B}$ phase was probably below the detection limits of the XRD analysis. Further microscopy and EDS analyses were performed to investigate these theories.

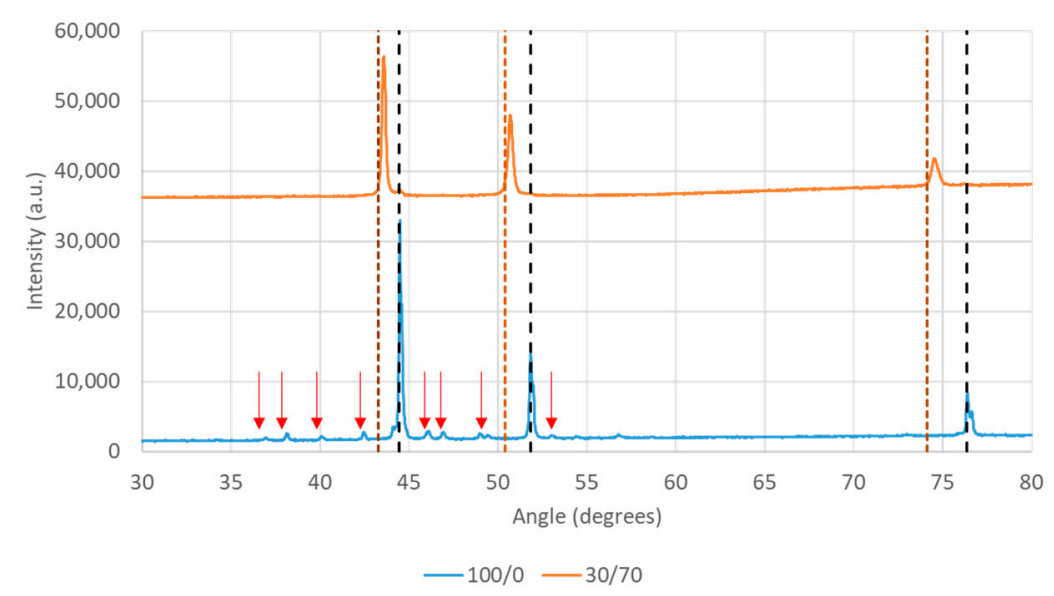

Figure 5. Peak patterns of $100 / 0$ and 30/70 from X-ray diffraction analysis. The black dotted line represents the peak pattern of elemental nickel, and the copper-red dotted line represents the peak pattern of elemental copper. The red arrows indicate the peak positions of the nickel boride phase $\left(\mathrm{Ni}_{3} \mathrm{~B}\right)$.

The optical microscopy images of both the 100/0 and 30/70 deposits are shown in Figure 6. From these microstructure images, a relatively finer dendritic microstructure was seen in the 100/0 deposits when compared to $30 / 70$ deposits (realized through the measurement of secondary dendrite arm spacing). In both cases, the microstructure was constituted of two phases. The 100/0 composition is in the hypoeutectic region of the $\mathrm{Ni}-\mathrm{Ni}_{3} \mathrm{~B}$ eutectic point. The dendritic phase is expected to be a nickel-silicon solid solution (silicon is completely soluble at these levels), and the inter-dendritic phase is likely to be an eutectic phase with nickel and nickel boride. The coarsening of dendrites in the case of the 30/70 samples could be attributed to the lower powder capture efficiency. Due to the low capture efficiency, most of the energy is anticipated to be absorbed by the deposit; therefore, more remelting between successive layers is expected. However, validating these claims was not feasible, since there were no markers to identify the layer boundaries in the 30/70 microstructure. A repetitive coarsened dendrite band pattern was observed in the 100/0 deposits. This pattern is expected to be a signature of the layer-by-layer deposition. Similar microstructural features have been reported in the dendritic microstructures of aluminum deposits [34] and 17-4PH steel deposits [35]. The formation of these coarsened dendrite bands was attributed to remelting occurring between layers during LMD. 


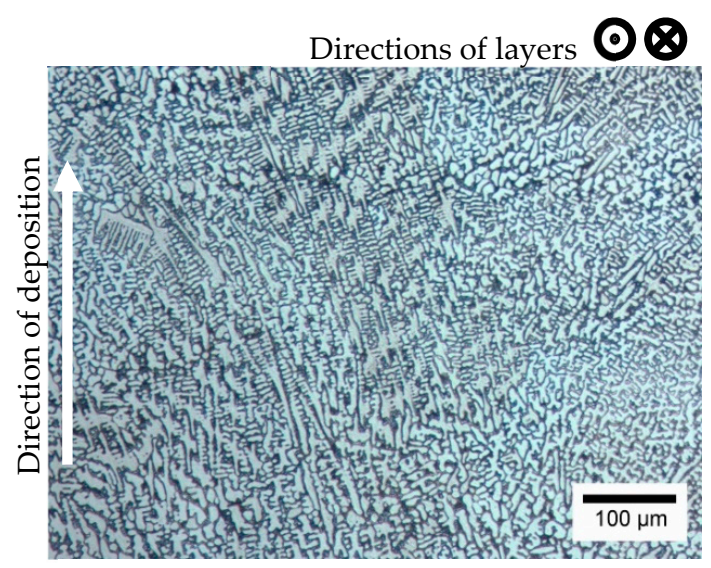

(a)

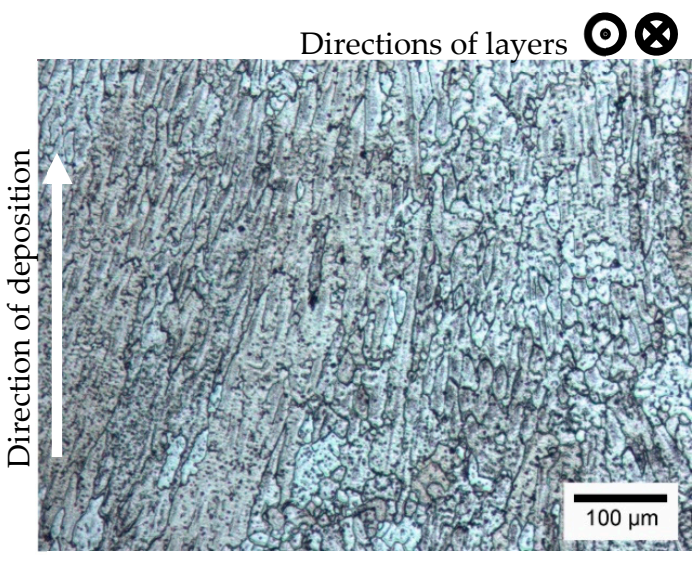

(b)

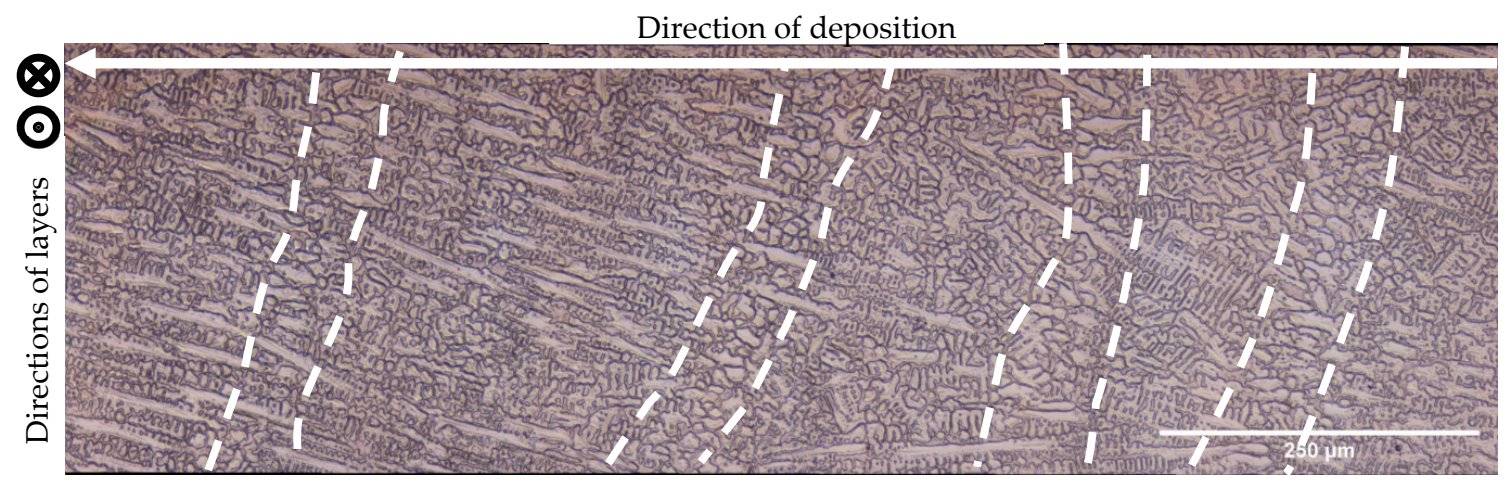

(c)

Figure 6. Optical microscope images of transverse sections of (a) the 100/0 nickel-rich deposit and (b) the 30/70 copper-rich deposit (c) bands of coarsened dendrites on 100/0 deposits, suspected to originate from remelting during successive layer-by-layer deposition.

At relatively higher magnifications, apart from the copper-nickel solid solution and the nickel boride phases, a third phase of inclusions was also observed. These inclusions were suspected to be silica particles. These particles were mostly situated in the inter-dendritic phase. A bright-field optical microscope image with Nomarski interference contrast is shown in Figure 7. The dark phase in the image is suspected to be silica inclusions.

In order to validate the presence of the nickel boride as the inter-dendritic phase, and to also investigate its presence in a 30/70 deposit, standard-less EDS analysis was performed. A line scan EDS analysis across the dendritic and inter-dendritic phases is shown in Figure 8. Boron is a low atomic number element, and is therefore not easily detectable using the SEM. However, the presence of this phase was realized through the variation in copper-nickel content across the phases. The complimentary rise and drops seen in the counts of copper and nickel are attributed to the absence of copper, and the presence of nickel boride as the inter-dendritic phase. EDS analysis also revealed that as-deposited compositions were within $4 \mathrm{wt}$. \%. difference from as-blended compositions. 


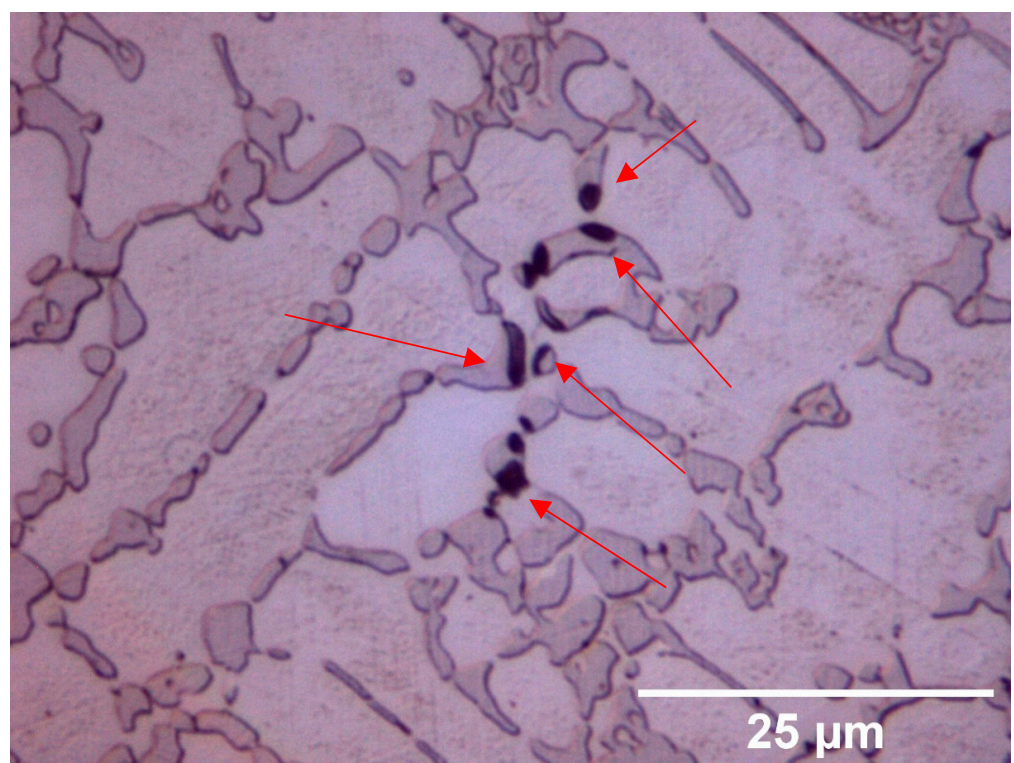

Figure 7. Optical microscope image of 100/0 nickel-rich deposit taken by using Nomarski interference contrast. The elevated inter-dendritic phase is nickel boride, whereas the dendritic phase is the nickel phase. The dark-phase particles (annotated by the red arrows) are suspected to be silica inclusions.

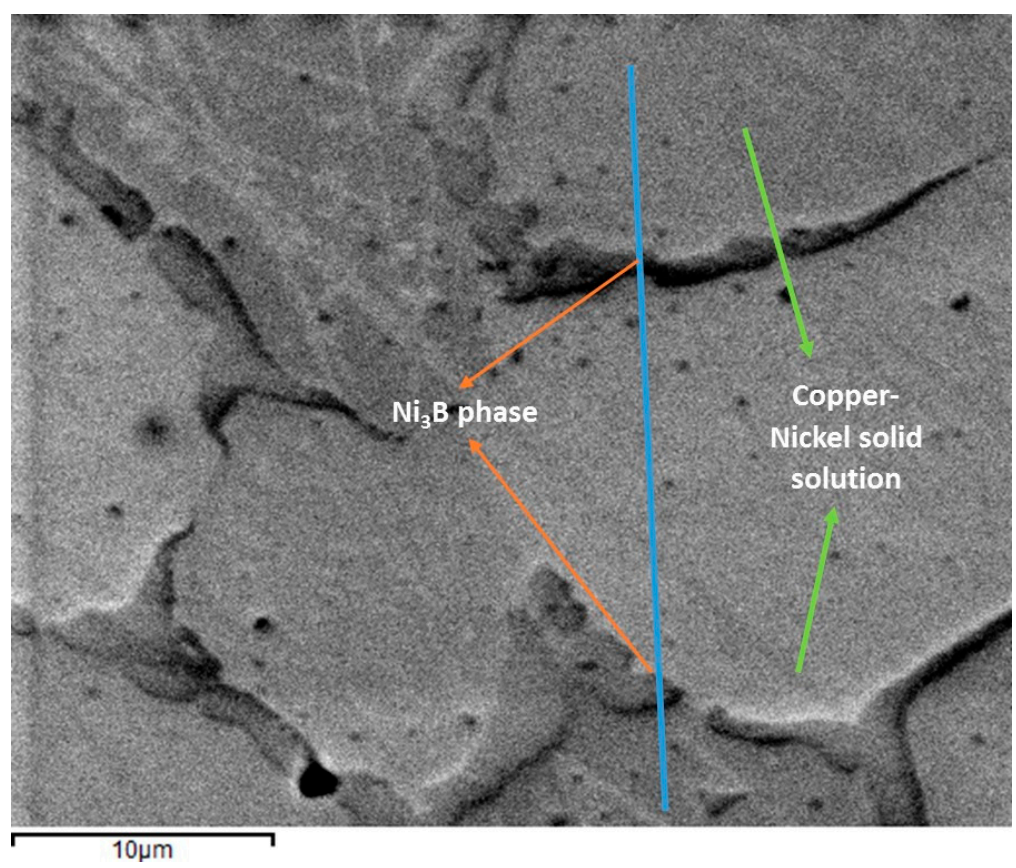

(a)

Figure 8. Cont. 


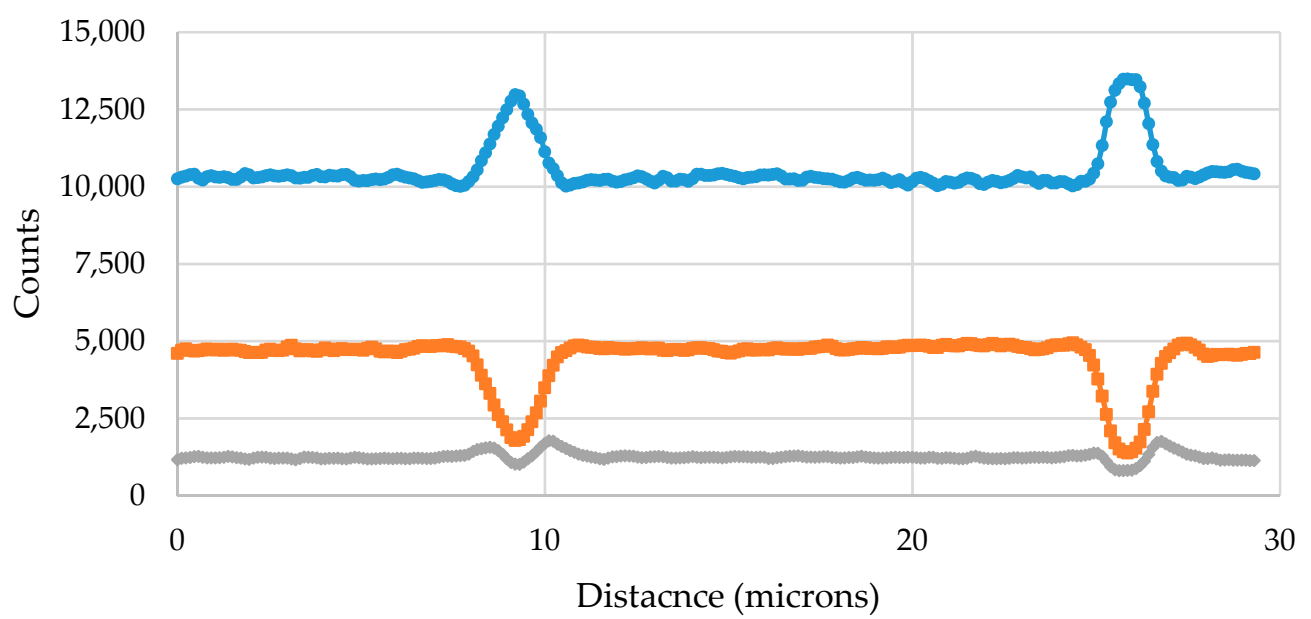

$\multimap$ Nickel Ka1 $\quad-$ Copper Ka1 $\longrightarrow$ Silicon Ka1

(b)

Figure 8. EDS line scan analysis across the dendritic and inter-dendritic phases on an as-polished $30 / 70$ deposit. The complementary rises and drops in the copper and nickel counts are indicative of the presence of nickel boride as the inter-dendritic phase.

\subsection{Dissimilar Graded Material Deposition}

FGM deposits of 100/0 over 30/70 and vice versa were deposited onto the AISI 304 substrates. In each case, the first material was deposited for 40 layers, then the powder was swapped out to deposit the second material. At a dissimilar material interface, the duty cycle of power was ramped down from a higher value to optimized conditions. This ramp down was performed as three sets (see Figure 2), and it was repeated for $100 / 0$ on $30 / 70$ and $30 / 70$ on $100 / 0$.

Typically, before starting the deposition, preheating is performed by running the laser without powder. This is intended to reduce the temperature gradient during the actual deposition. This aids in attaining good bonding with the substrate, and is therefore good practice in situations where this bond is of significance. In this study, this preheat scan was not performed, as starting deposition with the optimized conditions might lead to insufficient bonding or a flawed start in a deposition. However, starting at a higher duty cycle enables one to lower the temperature gradient and attain a flaw-free start. However, the higher duty cycle could produce larger melt pools and different volumes of deposited material. In this study, this phenomenon was leveraged to alter the grading in the deposited material. At the dissimilar material interface, different starting values of duty cycles were theorized, to create differences in dilution, and therefore, differences in the grading schemes were expected. A graded material deposit of $30 / 70$ on 100/0 with the set 3 (see Figure 2) duty cycle ramp down is shown in Figure 9.

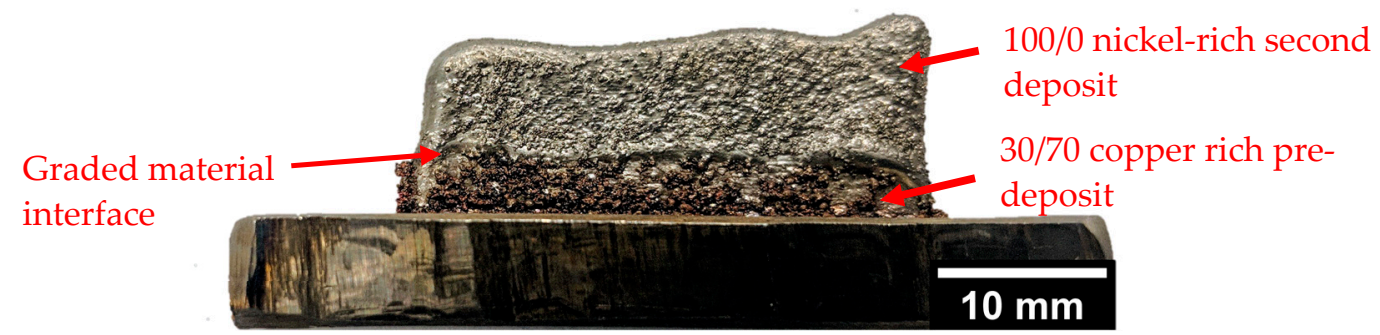

Figure 9. Copper-nickel FGM deposit fabricated with $30 / 70$ as the pre-deposit and $100 / 0$ as the second deposit. The set 3 duty cycle rampdown parameter was used at the dissimilar material interface. 
In order to realize the chemical gradient, transverse and longitudinal sections of these deposits were prepared for optical microscopy, hardness testing, and EDS analysis. The initiation of grading, i.e., the dissimilar material interface, was optically distinguishable, due to the difference in the reflectivities of the polished surfaces. This difference was also apparent from the oxide scale, and a clear demarcation between the two dissimilar materials was observed when they were cut using a wire-EDM. The transition in microstructure can be seen from Figure 10. A clear transition in the microstructure, from the relatively finer two-phase dendritic microstructure, to a coarser two-phase microstructure, can be seen.

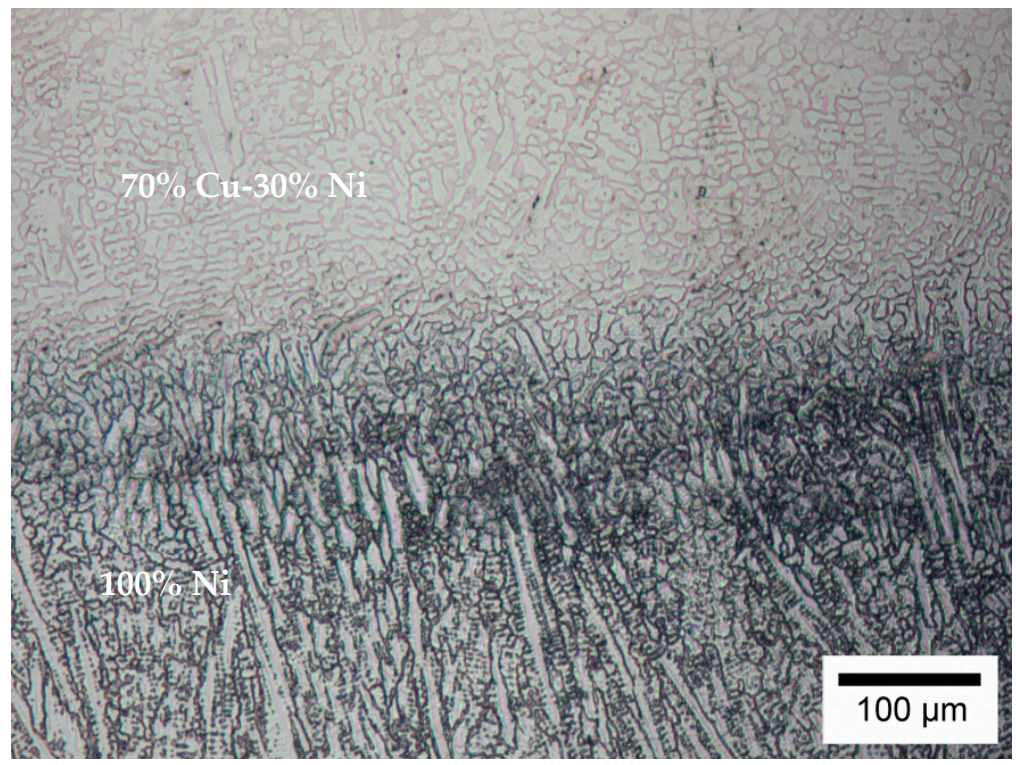

Figure 10. Optical microscope image of the dissimilar material interface on a graded material deposit fabricated by depositing 30/70 on 100/0 using the set 1 duty cycle ramp (see Figure 2).

Line scan EDS analysis was performed to realize the variations in chemistry across the height of the deposit. The nickel, copper, and silicon contents were monitored to realize the trend and nature of grading. The line scan plots are shown in Figures 11 and 12. The x-axis of these plots traverses along the height from the pre-deposit on the left, to the second deposit on the right, on the axis.

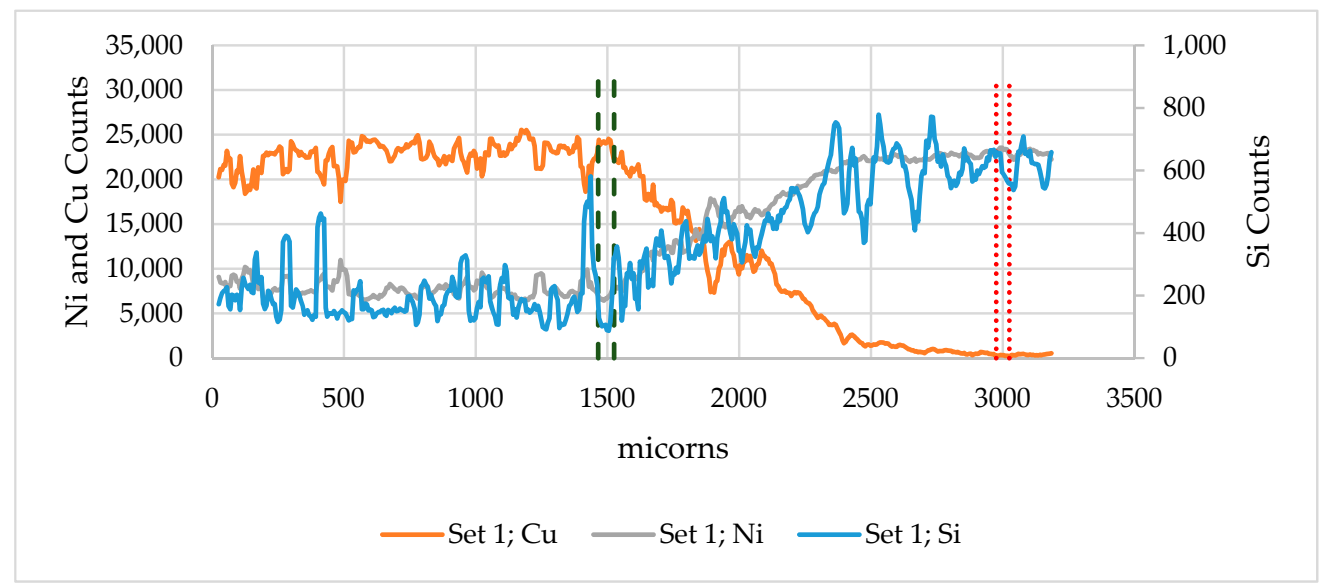

(a)

Figure 11. Cont. 


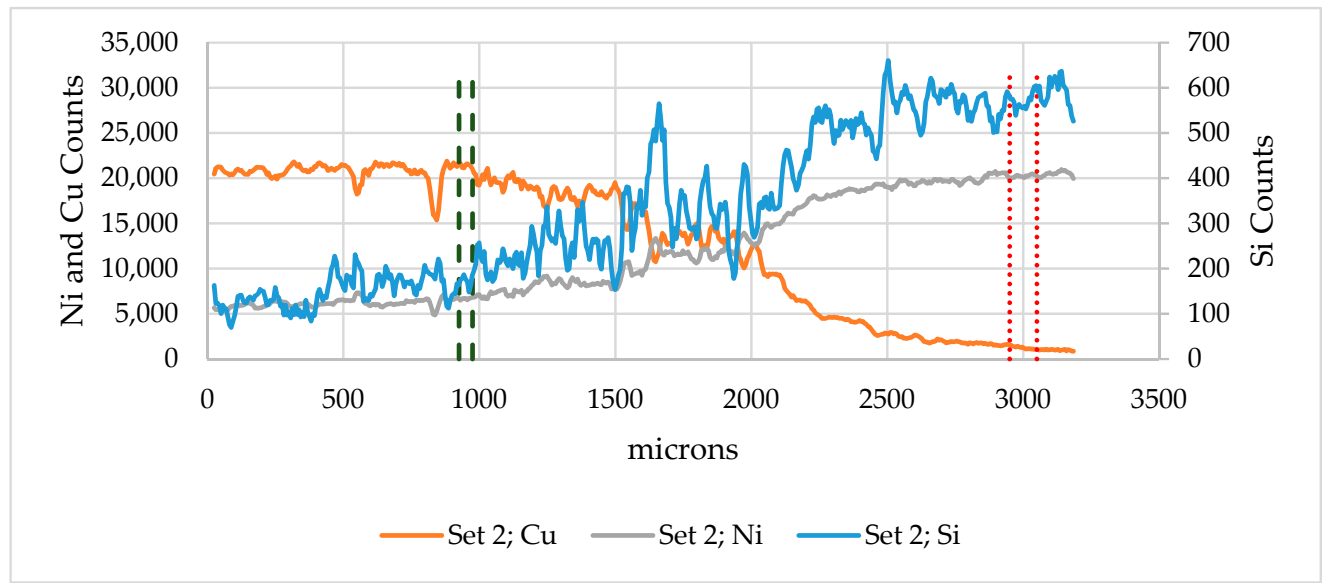

(b)

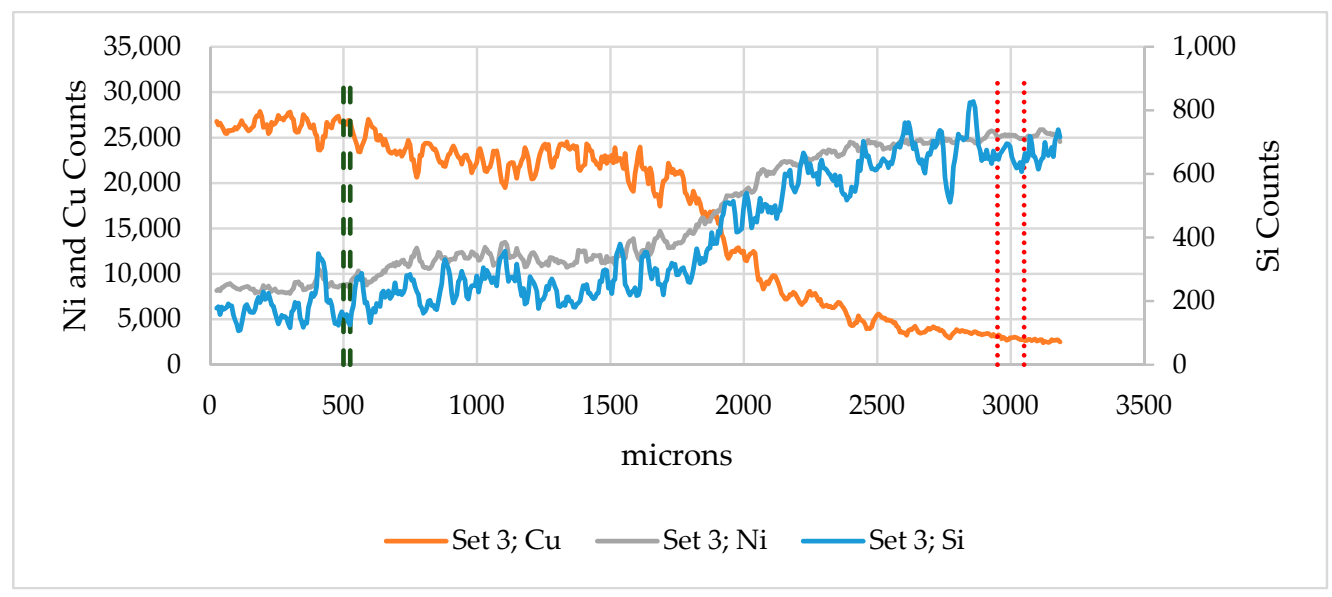

(c)

Figure 11. EDS line scan analyses across dissimilar graded material interfaces for the three sets, (a) set 1 , (b) set 2 and (c) set 3, of duty cycle ramp downs (see Figure 2) when 100/0 nickel-rich deposit was fabricated on 30/70 copper-rich pre-deposit. Dashed lines indicate the approximate locations of start (dark green) and end (bright red) points of the transition region.

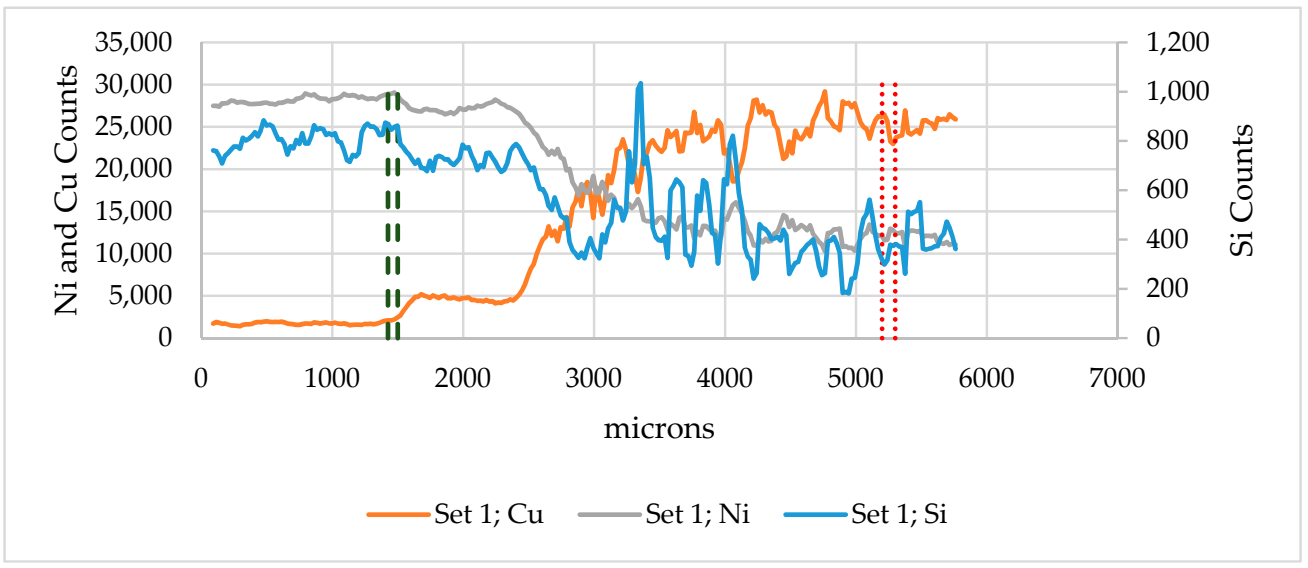

(a)

Figure 12. Cont. 


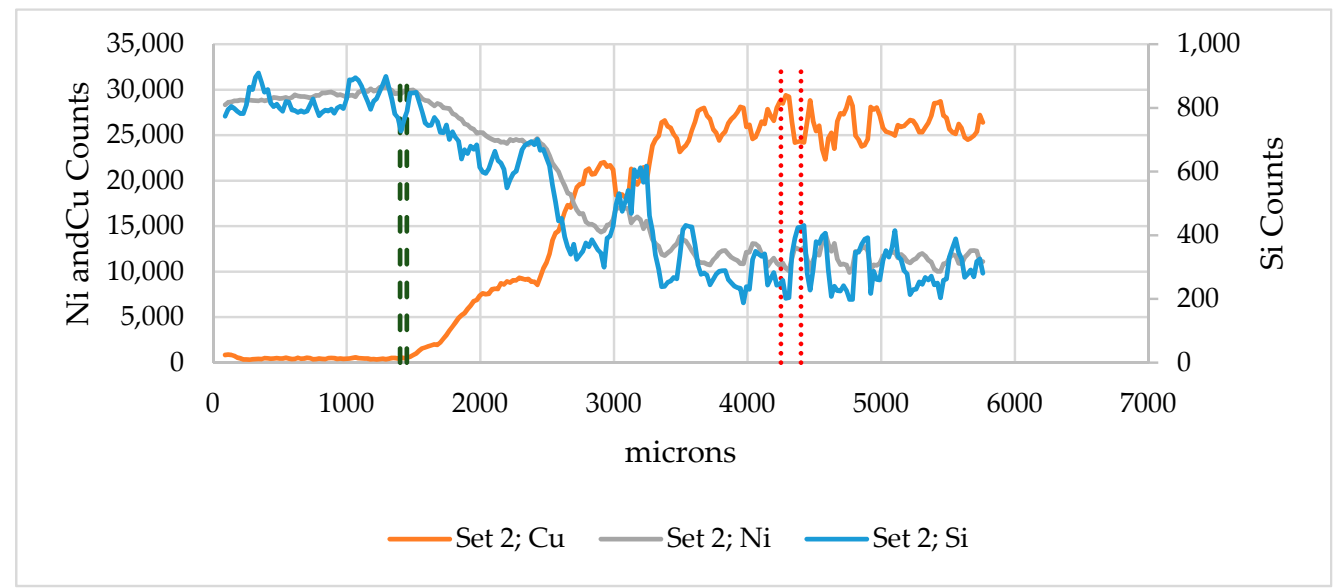

(b)

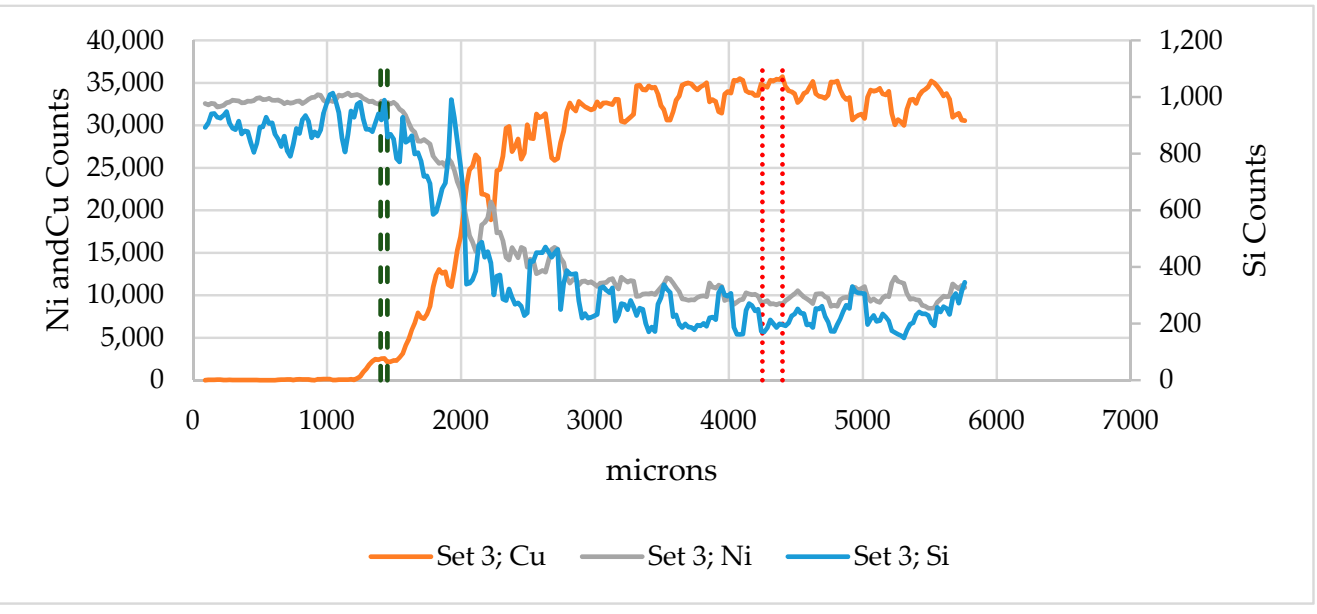

(c)

Figure 12. EDS line scan analyses across dissimilar graded material interfaces for the three sets, (a) set 1 , (b) set 2, and (c) set 3, of the duty cycle ramp downs (see Figure 2) when 30/70 copper-rich deposits were fabricated onto the $100 / 0$ nickel-rich pre-deposit.

The differences in the chemistry gradient with changing duty cycle and deposition combinations are apparent, from Figures 11 and 12. The transition in chemistry was identified through the significant slope changes in the count signals of each element. From Figure 11, from set 1 to set 3 , the transition length was observed to increase, and intermediate steps were also observed to occur. From set 2 to set 3 , the length of this intermediate step was also seen to increase. On the other hand, from Figure 12, the length of the transition region was observed to decrease. Similar to the scans in Figure 11, the intermediate steps in the composition were also seen in the plots in Figure 12. However, these steps were noticed to decrease in length, and disappear with an increasing duty cycle. Also in all of the above line scans, a complementary rise/drop can be seen in the copper and nickel count signals, this is attributed to the presence of the nickel boride phase. This behavior was similar to the observations from the EDS line scan shown in Figure 8. While the introduction of copper was always apparent, pinpointing the exact start/end of the transition within the 30/70 deposits using copper counts was challenging. Variations in silicon counts were used to aid with this decision. However, there was a lot of noise in the data due, to the Si content variation within the dendritic and interdendritic phases. This lead to uncertainty within the exact transition length measurements. In the case of 30/70 to 100/0 deposition, from set 1 to set 3 , the length of the transition was observed to increase monotonically. In order to better realize the differences among these deposits, the length of the chemical gradient from 
Figures 11 and 12 was measured and plotted in Figure 13. From set 1 to set 3 , this length was observed to more than double with an increasing duty cycle. In the case of 100/0 to 30/70 however, the length of the chemistry transition was observed to decrease. However, these values were still larger than the largest transition length seen, in the case of $100 / 0$ on $30 / 70$ deposits. The scale of the drop in transition length was also not as substantial.

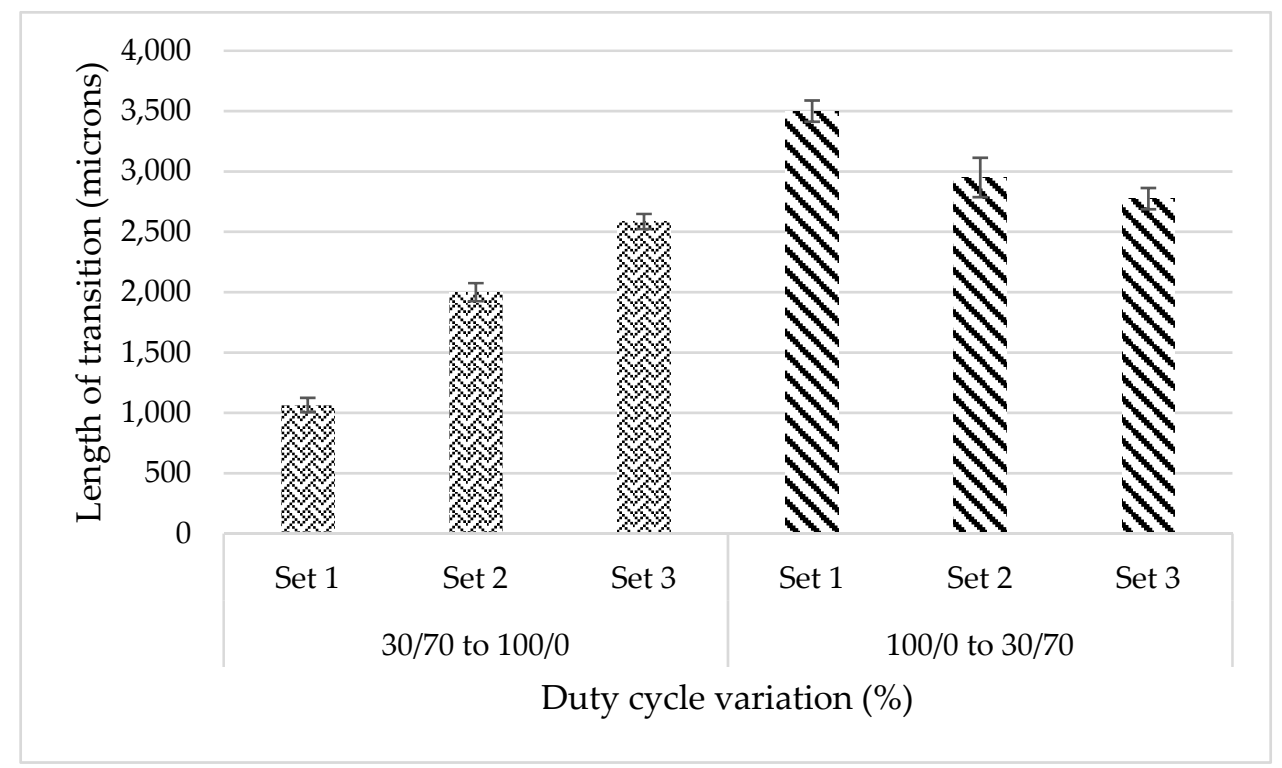

Figure 13. Length of the chemical gradient for the different cases of graded material depositions, as measured from Figures 11 and 12.

From set 1 to set 3 , the initial values of the duty cycle were increased. This increased the results of the increase in energy input during the deposition of the initial layers. This higher energy was expected to result in a larger melt pool depth and deposited volume. However, due to the rampdown of the duty cycle in successive layers, the remelting was expected to decrease as the deposition progressed. This difference in remelting depth was theorized to create a gradual and tailorable gradient. However, if the rampdown of the duty cycle was insufficient, the remelt could be significant enough to rewrite the gradient established in the previous layer. This phenomenon is better explained in the schematic diagram shown in Figure 14. This gradient is also expected to be influenced by the amount of newly deposited material at the end of every layer. Therefore, the differences in capture efficiency of the $100 / 0$ and 30/70 blended powder are expected to give different outcomes. From the line scan data in Figure 11, the occurrence of the intermediate step in transition in set 2 and set 3 implies that the gradient was preserved across successive layers of deposition. With an increase in the duty cycle, greater dilution in seen from the pre-deposit. However, the gradient was retained across layers. In the case of 30/70 on $100 / 0$, Figure 12, with an increase in the duty cycle, the remelting was expected to increase, and the gradient was completely changed between successive layers of deposition. This difference is suspected to be a consequence of the difference in the capture efficiency of the feedstock powders. 


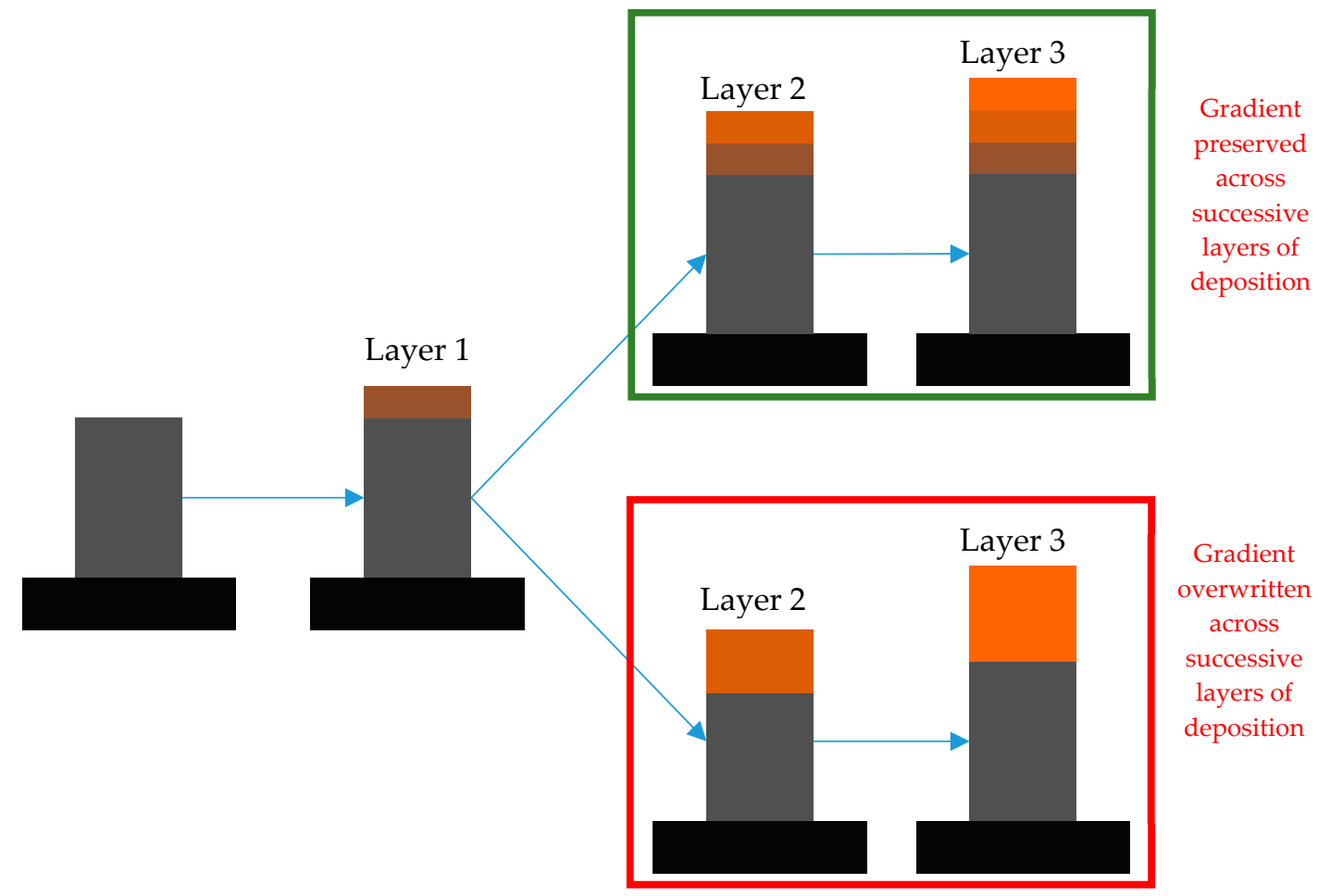

Figure 14. Schematic diagram of transverse sections of FGM deposits detailing the influence of remelting on gradient development during dissimilar material deposition.

In order to assess the influence of varying transition lengths on mechanical properties, hardness testing and tensile testing were performed. Hardness testing was performed on a Struers Duramin hardness tester. A load of $200 \mathrm{~g}$ and a dwell time of $5 \mathrm{~s}$ were used for measuring hardness. A series of indentations were made along the height of the deposit to track the hardness variation with the changing chemistry of the deposit. The hardness data from the deposits are shown in Figure 15. The interface shown in Figure 10 was positioned as the center for the hardness analysis. The 30/70 deposits were observed to have to a significantly lower hardness in comparison to the $100 / 0$ deposits. This steep difference can be used to realize the variation in chemistry. The drop/rise in hardness along the chemical gradient was observed to correlate well with the transition lengths measured from EDS analysis. The longest transition lengths as measured from EDS, i.e., set 1 for 100/0 to 30/70 and set 3 for 30/70 to 100/0, showed a very gradual change in hardness. The shortest transition lengths as measured from the EDS analysis, i.e., set 3 for 100/0 to 30/70 and set 1 for 30/70 to 100/0 showed a relatively steep change in hardness.

As seen from the hardness values with increasing copper content, the hardness should be decreasing. Similarly, a significant difference in strength was also expected; thereby, failure was expected to always occur in the $30 / 70$ portion of the graded material. The deformation in the tensile specimens should also vary with composition. To investigate these claims, tensile testing of miniature specimens coupled with DIC analysis was performed. These miniature tensile specimens were prepared with the interface seen in Figure 10 located at approximately the center of the gage length. The gage length of these specimens was only $3 \mathrm{~mm}$, so it was possible that the entire transition length was not located within the gage length. This approach was adopted as it was easy to visually identify the interface. This enabled a reliable and repeatable method for locating the interface and for preparing tensile specimens. 


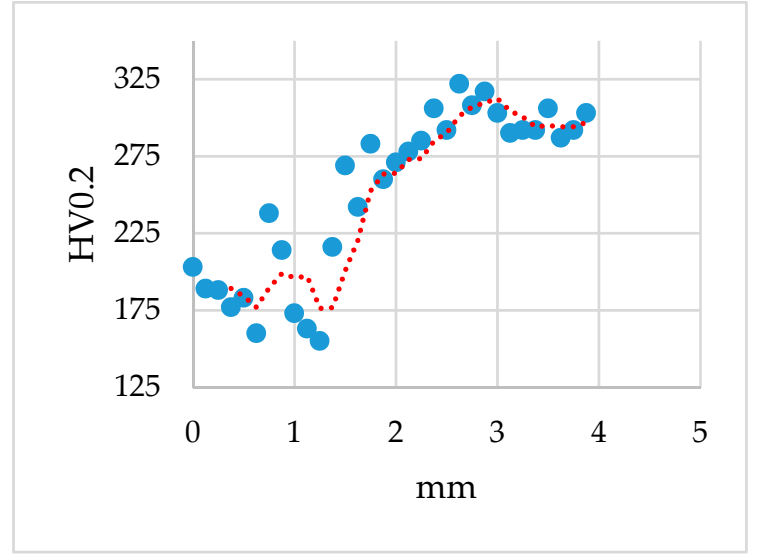

(a)

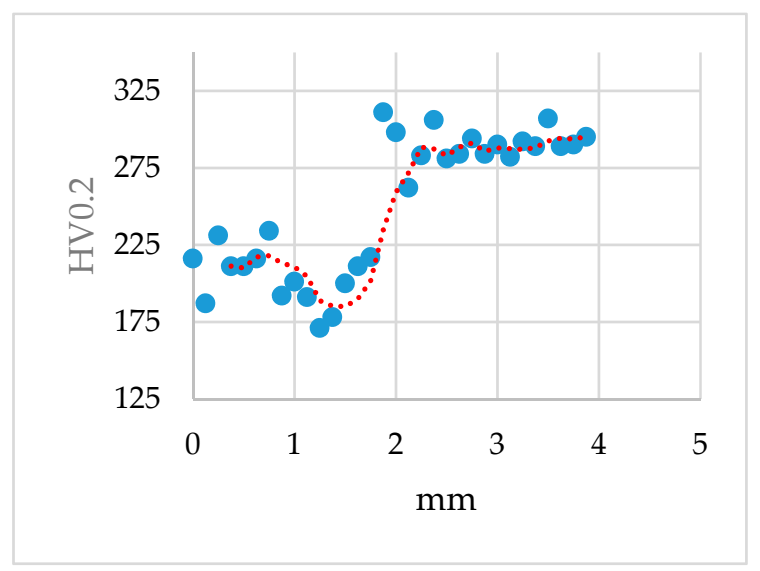

(c)

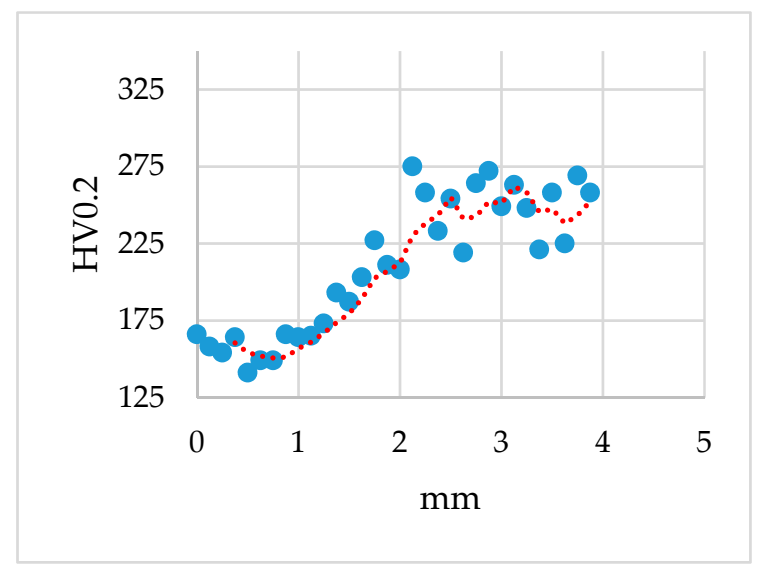

(e)

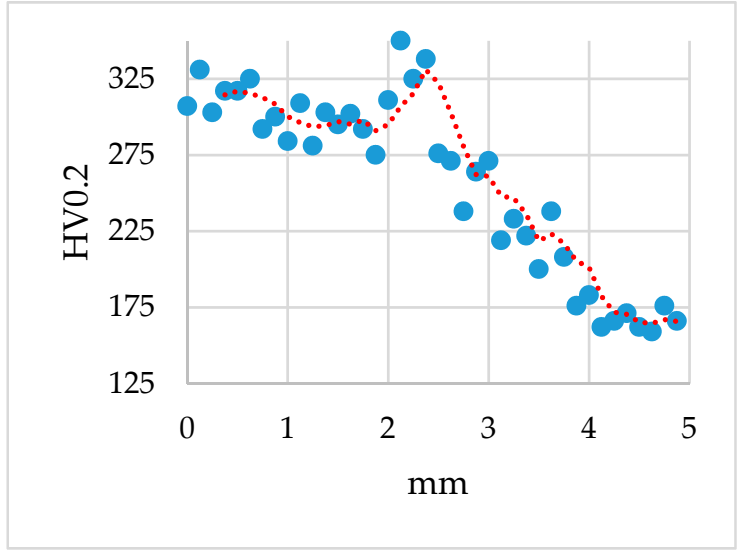

(b)

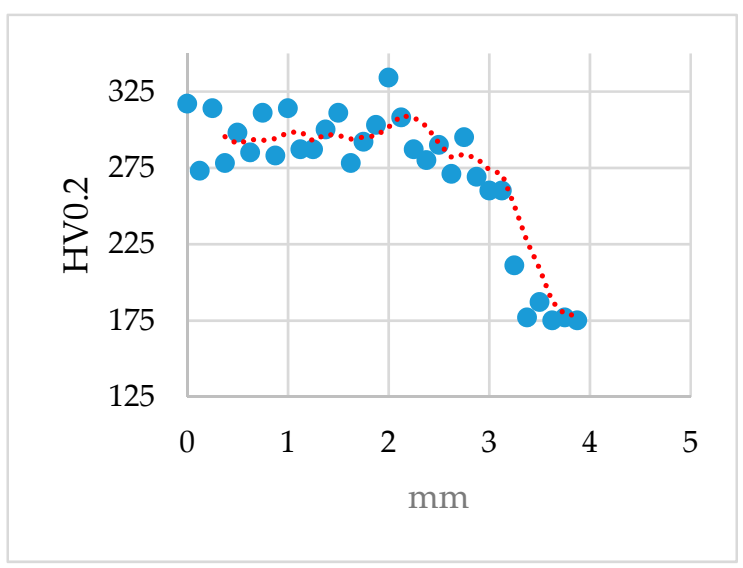

(d)

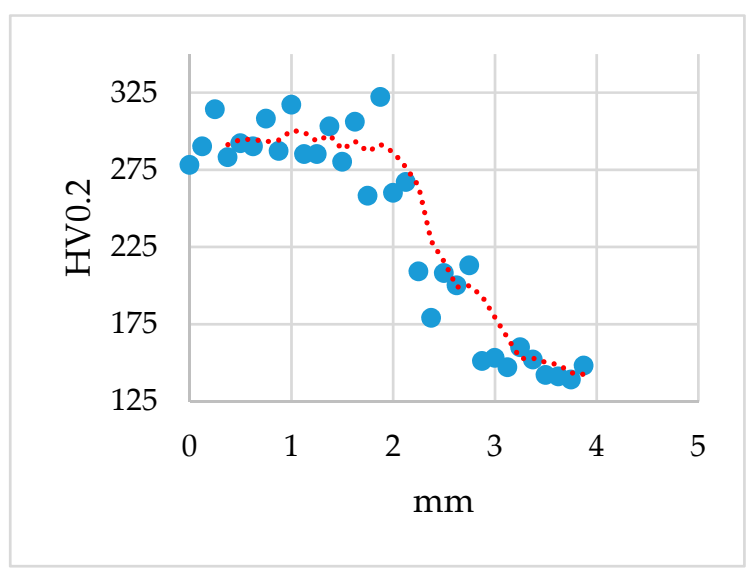

(f)

Figure 15. Variation in Vickers hardness values (HV0.2) along the height ( $\bullet$ is the spot measurement and the red dotted line is the moving average trend line with four measurements as the period) of the graded material deposits. (a,c,e) are the hardness plots on set 1, set 2, and set 3 deposits of 100/0 on $30 / 70$, respectively. $(\mathbf{b}, \mathbf{d}, \mathbf{f})$ are the are the hardness plots of set 1 , set 2 , and set 3 depositions of 30/70 on $100 / 0$, respectively.

Since the differences in the transition lengths were significant for set 1 and set 3 duty cycle rampdowns for $100 / 0$ on both the $30 / 70$ and $30 / 70$ deposits, miniature tensile specimens were cut and tested from these deposits. The interface was located at the center for the gage length, for all of 
the specimens. The specimens were tested at a constant crosshead speed of $0.6 \mathrm{~mm} / \mathrm{min}$. The tensile tests were video-recorded, with the camera being oriented to capture the front view of the tensile testing. These videos were processed for DIC analysis and strain field estimation. A speckle pattern was necessary to create sufficient contrast for DIC analysis. The required speckled pattern was applied to all of the specimens before tensile testing. The DIC-estimated strain fields during tensile testing post-initiation of necking is shown in Figure 16.

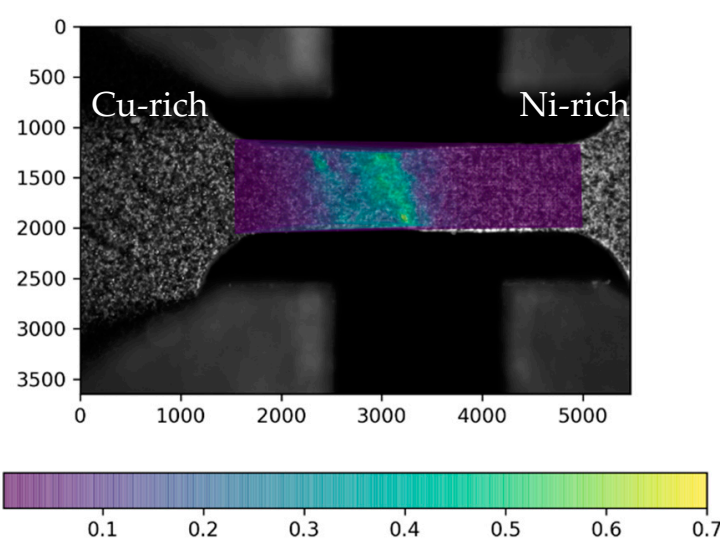

(a)

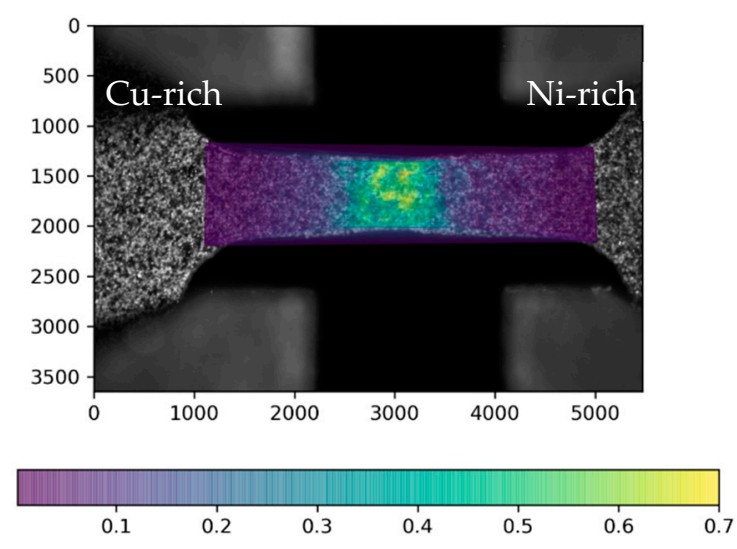

(c)

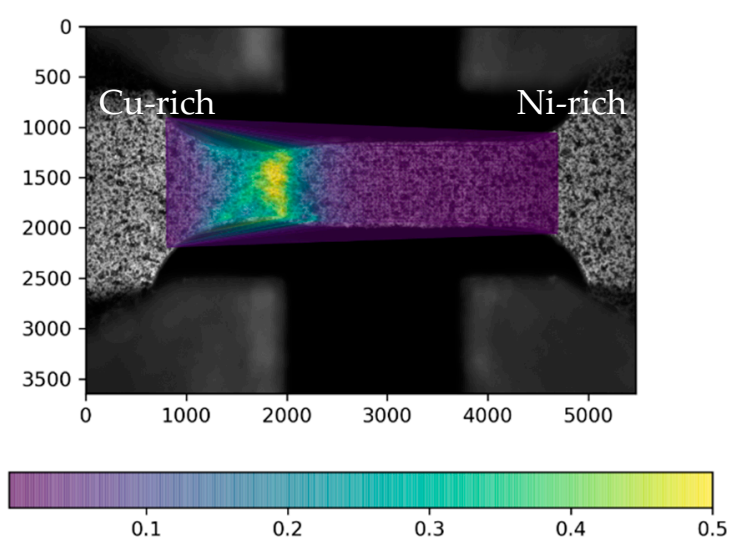

(b)

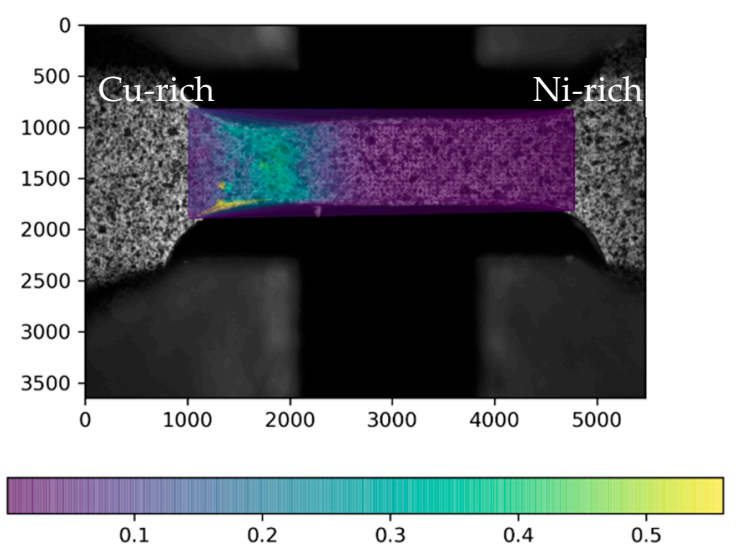

(d)

Figure 16. Strain fields from the gage length elongation values calculated from DIC analysis for: (a) Set 1 100/0 on 30/70, (b) Set $130 / 70$ on 100/70, (c) Set $3100 / 0$ on 30/70, and (d) Set $330 / 70$ on 100/0 deposits.

From the strain fields shown in Figure 16, the inhomogeneity in strain along the gage length was recognizable. As anticipated from the hardness data, the failure was pushed into the weaker copper-containing region. The majority of the plastic deformation was limited to the portion of the gage length that contained copper. Minimal to no deformation was observed in the 100/0 side of the deposit. The steep change in the strain field along the gage length was expected to be indicative of the start of the chemistry gradient. The beginning of the failure was expected to differ, depending on the length of the transition region and position of the start of the interface within the gage length. Among all of the specimens tested, the failure was always noted to occur within the copper-containing region. The exact chemistry at the site of failure initiation was difficult to pinpoint, due to the inclined nature of the fracture site.

The strength and ductility values of tested specimens are shown in Figure 17. Since the start of the interface was located at the middle of the gage length, the transition region did not necessarily end within the gage length. The length of the transition region was larger in the 30/70 on 100/0 deposits, 
in comparison to the $100 / 0$ on 30/70 deposits. This implies a lower copper content in the $30 / 70100 / 0$ tensile specimens. This was reflected in the ultimate strength values. Lower copper contents in these deposits were expected to have yield higher strengths.

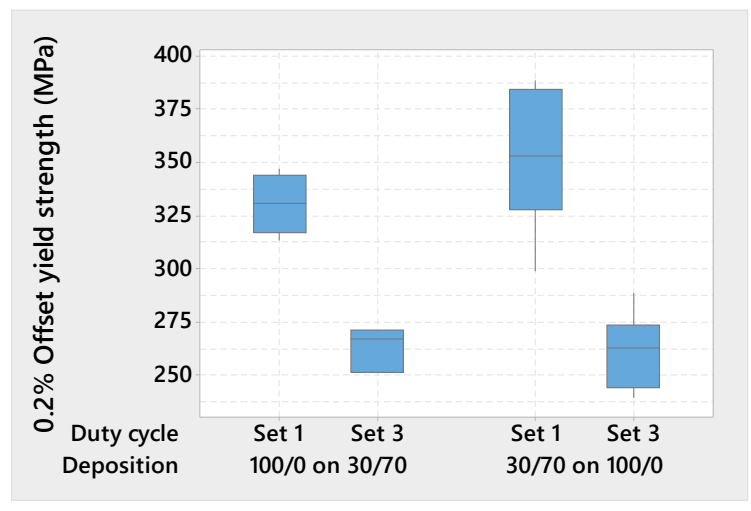

(a)

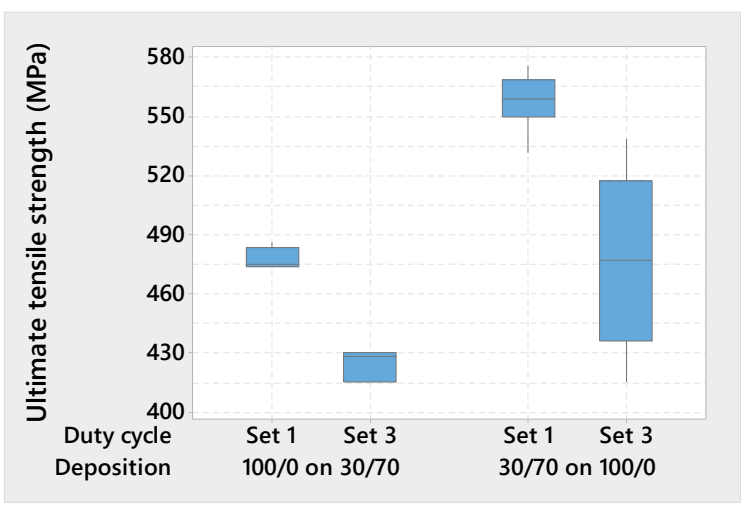

(b)

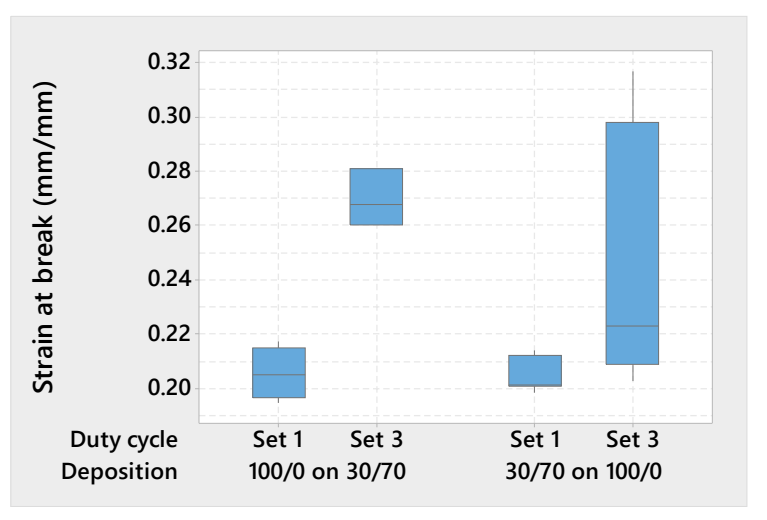

(c)

Figure 17. Box-and-whisker plots of (a) $0.2 \%$ offset yield strength, (b) ultimate tensile strength, and (c) strain at break from the crosshead displacement for the miniature tensile specimens prepared from deposits of different combinations. The box spans the 25th and 75th quartile, the vertical lines indicate the range between the minimum and maximum values, and the horizontal line indicates the median value.

The strain at break was used to assess the ductility of the specimens. With increasing duty cycle values, the values of strain at break were seen to increase. This is reflected in the median values shown in Figure 17c. This change was complementary to the variation observed in the strength values. Also, the difference in the median values varied with the deposition sequence. However, no statistically significant differences in mean values were observed with varying the deposition sequence. This would be attributed to the wide scatter seen specimens of set 3, 30/70 on 100/0.

In order to further assess the development of the inhomogeneous strain distribution, the strain measurements along the center line of the gage length at different strain values were charted. The trends in strain can be seen in Figure 18. From Figure 18, the variation and evolution of strain along the center line of the gage length can be observed. The distinction between the nickel-rich and copper-rich sections of the gage length is obvious, from the significant difference in strain values along the center line. At relatively low values of overall strain, such as 5\% cross-head strain, a gradual rise in strain from the inflection point can be observed. However, as the overall strain increases, the initiation of localized strain was seen. This was observed to always occur within the copper-rich side of the specimens, and away from the interface. This suggests good bonding between the deposit and the 
pre-deposit in all cases of deposition. This was also indicative of failure within the copper-rich side, and not at the interface of the deposit.

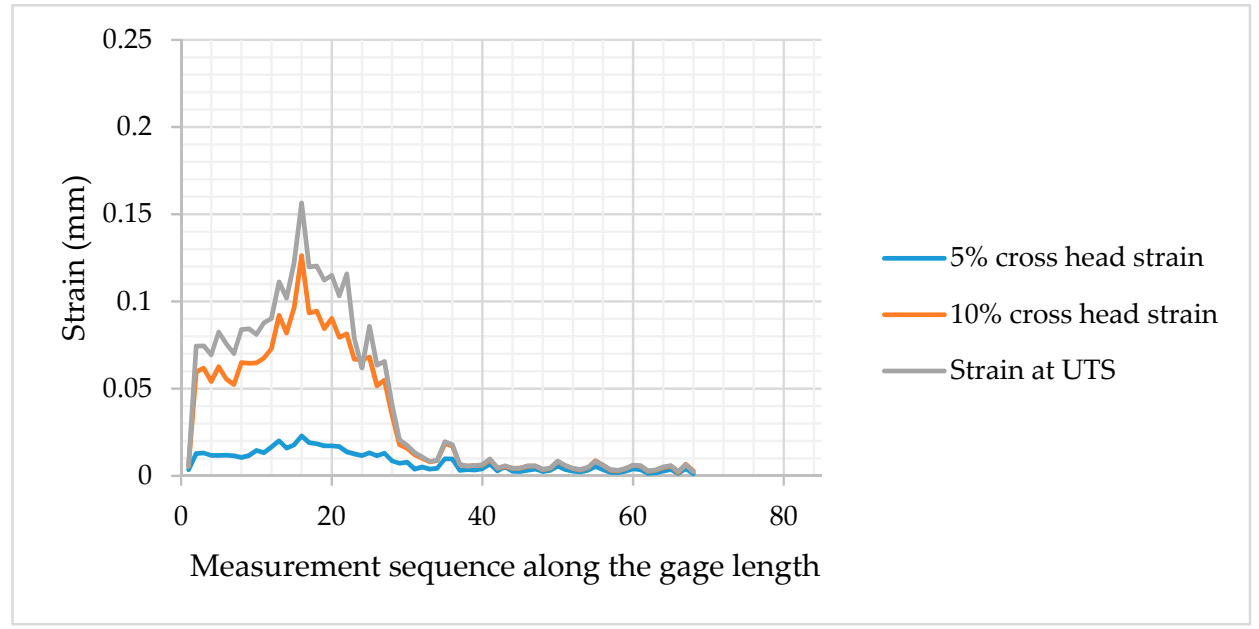

(a)

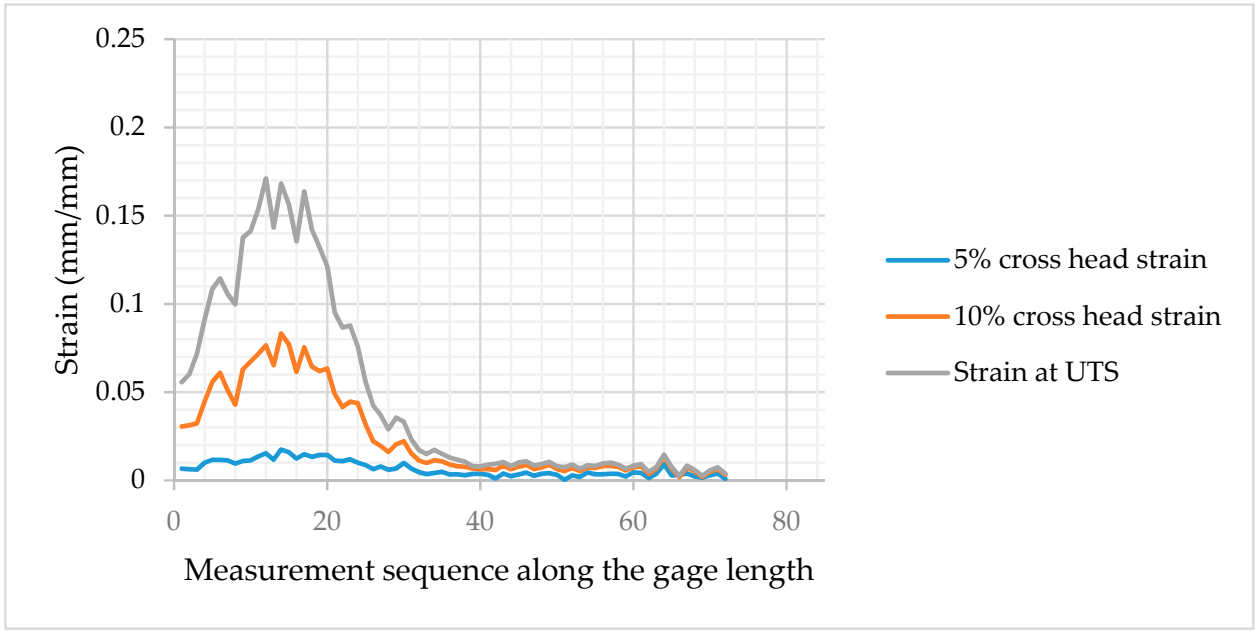

(b)

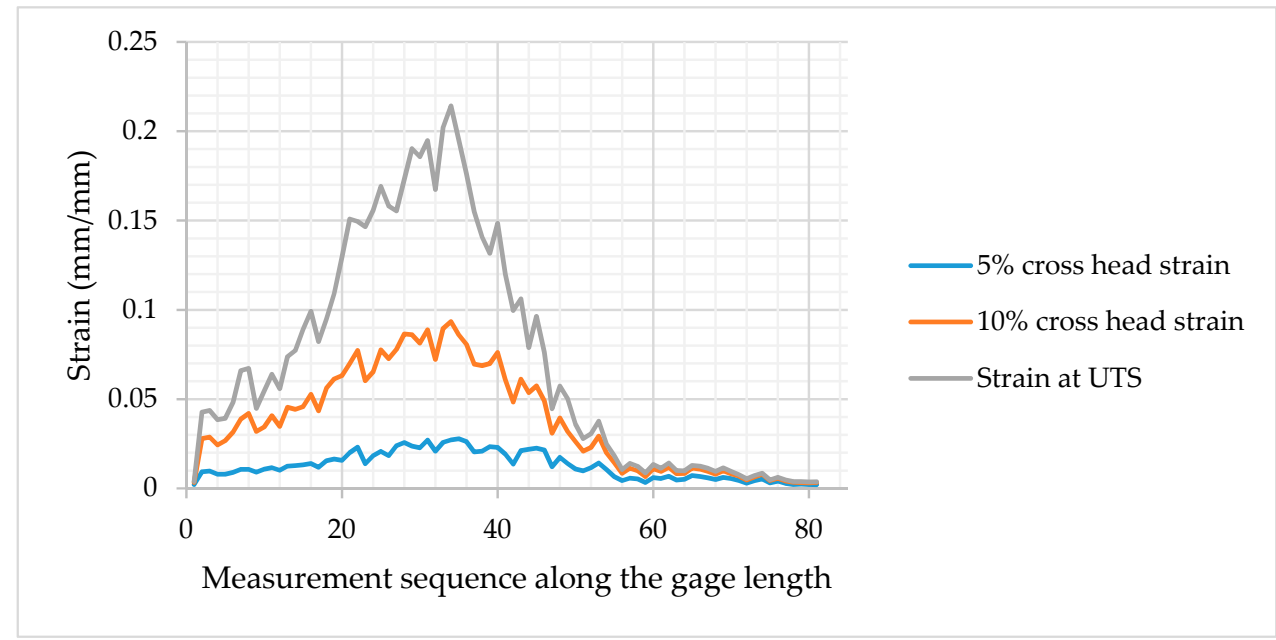

(c)

Figure 18. Cont. 


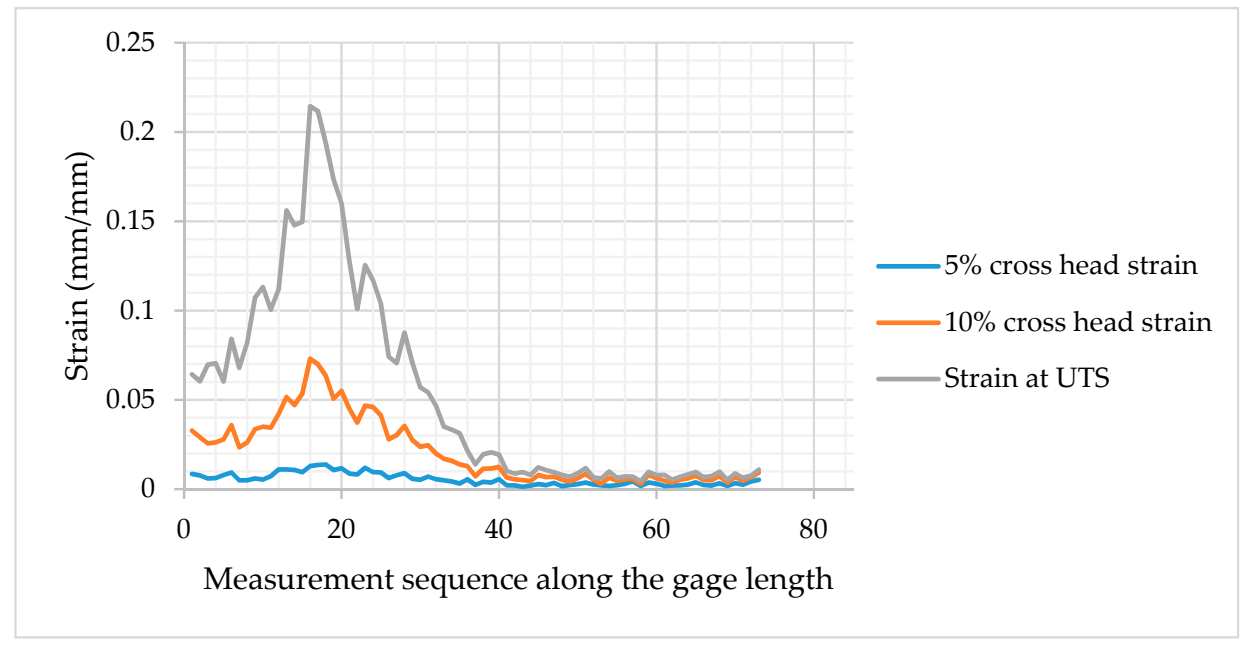

(d)

Figure 18. Strain values calculated along the center-line of the gage lengths of miniature tensile specimens cut from deposits of (a) Set 1 duty cycle for 100/0 on 30/70, (b) Set 1 duty cycle for 30/70 on 100/0, (c) Set 3 duty cycle for 100/0 on 30/70, and (d) Set 3 duty cycle for 30/70 on 100/0.

While the difference in strengths pointed to chemistry differences, the influence of the duty cycle was not as anticipated. For a given combination of pre-deposit and deposit, the change in transition length did not correlate with the strength variation. In both the cases, with an increasing duty cycle, the strength was seen to drop.

Previously, silica inclusions were observed within the deposit (see Figure 7). A compositional backscatter electron image of the fracture surface is shown in Figure 19. From the fracture surface, an inclusion situated inside the material can be clearly seen. Dimples probably originating from voids, and nucleated due to the presence of inclusions, can also be seen.

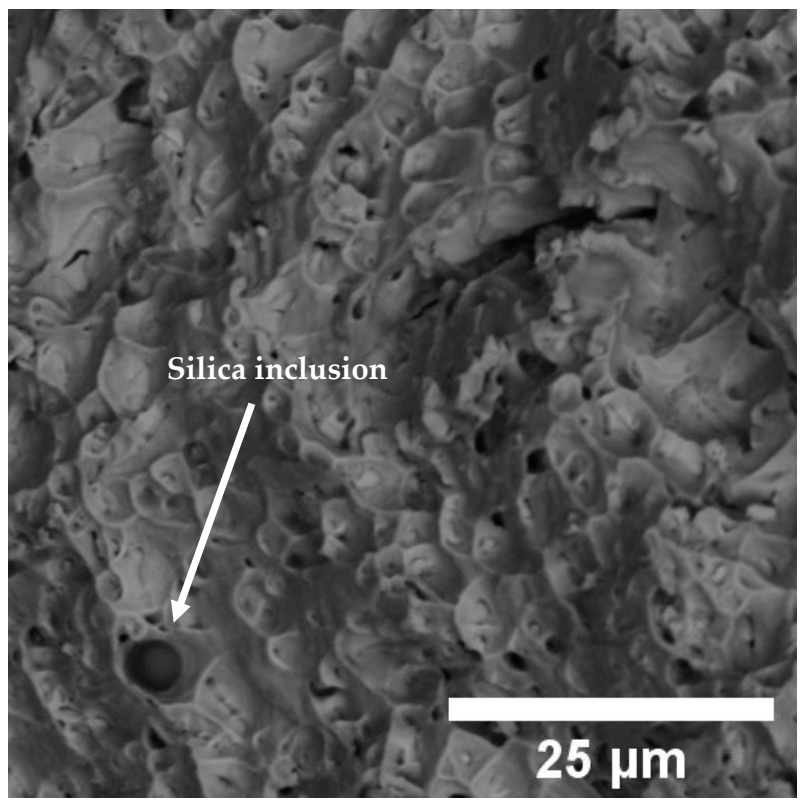

Figure 19. Silica inclusion on the fracture surface of a tensile specimen prepared from Set $330 / 70$ on a 100/0 deposit. 


\section{Conclusions}

- Utilizing pulsed width modulation to vary laser power was identified as a viable means for manipulating the chemical gradient in a graded material. Varying the duty cycle and the deposition sequence were shown to significantly alter the chemical gradient, and in some cases, the length of the gradient was observed to more than double.

- The deposition of copper on nickel or vice versa is not challenging, due to their mutual compatibility. While noticeable differences in grading schema were produced, no significant differences in deposition quality were noticed.

- Plastic deformation during tensile testing was almost entirely localized to the copper-rich end of the graded material specimens. From the median strain at break values, a significant change in ductility was observed with the changing deposition sequence. However, the statistical significance of this difference is questionable, due to the scatter in the strain at break values.

- Due to the differences in chemistry gradients, different ultimate tensile strength values were obtained from the tensile specimens. While the strength values varied with deposition sequence, these variations did not correlate with the chemistry gradients.

- Strain field estimation using DIC during tensile testing revealed the localization of the strain to only the copper-containing area of the gage length. Within the copper-containing portion of the gage length, at low elongation values, a gradient in strain was observed. From the strain field analysis, the failure was believed to occur away from the dissimilar material interface.

- While distinguishable differences in chemistry gradients were achieved, their impacts on mechanical properties and deposition quality were not really substantial. However, these conclusions are only limited to the copper-nickel material fabricated in this study.

Author Contributions: For this research article, S.K. designed and performed the experiments, analyzed the data, and wrote the manuscript; Y.Z. performed the DIC analysis; F.L. and J.N. guided the research project.

Funding: This project was supported by Department of Energy Grant No. DE-SC0018879 and National Science Foundation Grant No. CMMI 1625736.

Acknowledgments: The support from Intelligent Systems Center, Center for Aerospace Manufacturing Technologies, and Material Research Center at Missouri S\&T is greatly appreciated.

Conflicts of Interest: The authors declare no conflict of interest.

\section{References}

1. Koizumi, M. FGM activities in Japan. Compos. Part B Eng. 1997, 28, 1-4. [CrossRef]

2. Doubrovski, E.L.; Tsai, E.Y.; Dikovsky, D.; Geraedts, J.M.P.; Herr, H.; Oxman, N. Voxel-based fabrication through material property mapping: A design method for bitmap printing. Comput. Des. 2015, 60, 3-13. [CrossRef]

3. Lee, W.Y.; Stinton, D.P.; Berndt, C.C.; Erdogan, F.; Lee, Y.-D.; Mutasim, Z. Concept of Functionally Graded Materials for Advanced Thermal Barrier Coating Applications. J. Am. Ceram. Soc. 1996, 79, 3003-3012. [CrossRef]

4. Miyamoto, Y.; Kaysser, W.A.; Rabin, B.H.; Kawasaki, A.; Ford, R.G. Functionally Graded Materials: Design, Processing and Applications; Springer Science \& Business Media: Berlin/Heidelberg, Germany, 2013; Volume 5, ISBN 1461553016.

5. Muller, P.; Mognol, P.; Hascoet, J.-Y. Modeling and control of a direct laser powder deposition process for Functionally Graded Materials (FGM) parts manufacturing. J. Mater. Process. Technol. 2013, 213, 685-692. [CrossRef]

6. Watari, F.; Yokoyama, A.; Omori, M.; Hirai, T.; Kondo, H.; Uo, M.; Kawasaki, T. Biocompatibility of materials and development to functionally graded implant for bio-medical application. Compos. Sci. Technol. 2004, 64, 893-908. [CrossRef]

7. Leushake, U.; Winter, A.N.; Rabin, B.H.; Corff, B.A. General Aspects of FGM Fabrication by Powder Stacking. Mater. Sci. Forum. 1999, 308-311, 13-18. [CrossRef] 
8. Thümmler, F. An Introduction to Powder Metallurgy; Institute of Materials: London, UK, 1993; ISBN 090171626X.

9. Marple, B.R.; Boulanger, J. Graded casting of materials with continuous gradients. J. Am. Ceram. Soc. 2016, 77, 2747-2750. [CrossRef]

10. Durejko, T.; Ziętala, M.; Polkowski, W.; Czujko, T. Thin wall tubes with Fe3Al/SS316L graded structure obtained by using laser engineered net shaping technology. Mater. Des. 2014, 63, 766-774. [CrossRef]

11. Wu, D.; Liang, X.; Li, Q.; Jiang, L. Laser rapid manufacturing of stainless steel 316L/Inconel718 functionally graded materials: Microstructure evolution and mechanical properties. Int. J. Opt. 2010, 2010, 1-5. [CrossRef]

12. Qian, T.; Liu, D.; Tian, X.; Liu, C.; Wang, H. Microstructure of TA2/TA15 graded structural material by laser additive manufacturing process. Trans. Nonferrous Met. Soc. China 2014, 24, 2729-2736. [CrossRef]

13. Ren, H.S.; Liu, D.; Tang, H.B.; Tian, X.J.; Zhu, Y.Y.; Wang, H.M. Microstructure and mechanical properties of a graded structural material. Mater. Sci. Eng. A 2014, 611, 362-369. [CrossRef]

14. Shah, K.; Haq, I.U.; Khan, A.; Shah, S.A.; Khan, M.; Pinkerton, A.J. Parametric study of development of Inconel-steel functionally graded materials by laser direct metal deposition. Mater. Des. 2014, 54, 531-538. [CrossRef]

15. Syed, W.U.H.; Pinkerton, A.J.; Liu, Z.; Li, L. Coincident wire and powder deposition by laser to form compositionally graded material. Surf. Coatings Technol. 2007, 201, 7083-7091. [CrossRef]

16. Liu, W.; DuPont, J.N. Fabrication of functionally graded TiC/Ti composites by laser engineered net shaping. Scr. Mater. 2003, 48, 1337-1342. [CrossRef]

17. Miyamoto, Y.; Kaysser, W.A.; Rabin, B.H.; Kawasaki, A.; Ford, R.G. Functionally Graded Materials-Design, Processing and Applications, 1st ed.; Springer US: New York, NY, USA, 1999; ISBN 978-1-4613-7419-0.

18. Shah, K. Laser Metal Deposition of Dissimilar and Functionally Graded Alloys. Ph.D. Thesis, The University of Manchester, Manchester, UK, 2011.

19. Yan, J.; Battiato, I.; Fadel, G.M. Planning the process parameters for the direct metal deposition of functionally graded parts based on mathematical models. J. Manuf. Process. 2018, 31, 56-71. [CrossRef]

20. Li, W.; Karnati, S.; Zhang, Y.; Liou, F. Investigating and eliminating powder separation in pre-mixed powder supply for laser metal deposition process. J. Mater. Process. Technol. 2018, 254, 294-301. [CrossRef]

21. Yan, L.; Chen, X.; Li, W.; Newkirk, J.; Liou, F. Direct laser deposition of Ti-6Al-4V from elemental powder blends. Rapid Prototyp. J. 2016, 22, 810-816. [CrossRef]

22. Zhang, J.; Zhang, Y.; Li, W.; Karnati, S.; Liou, F.; Newkirk, J.W. Microstructure and properties of functionally graded materials Ti6Al4V/TiC fabricated by direct laser deposition. Rapid Prototyp. J. 2018, 24, 677-687. [CrossRef]

23. Chen, X.; Yan, L.; Li, W.; Wang, Z.; Liou, F.; Newkirk, J.W. Effect of powder particle size on the fabrication of Ti-6Al-4V using direct laser metal deposition from elemental powder mixture. J. Mech. Eng. Autom. 2016, $6,348$.

24. Li, W.; Karnati, S.; Kriewall, C.; Liou, F.; Newkirk, J.; Brown Taminger, K.M.; Seufzer, W.J. Fabrication and characterization of a functionally graded material from Ti-6Al-4V to SS316 by laser metal deposition. Addit. Manuf. 2017, 14, 95-104. [CrossRef]

25. Ye, B.; Matsen, M.R.; Dunand, D.C. Blended elemental powder densification of Ti-6Al-4V by hot pressing. J. Mater. Res. 2011, 26, 965-969. [CrossRef]

26. Zhang, F.; Chen, J.; Tan, H.; Lin, X.; Huang, W. Composition control for laser solid forming from blended elemental powders. Opt. Laser Technol. 2009, 41, 601-607. [CrossRef]

27. Watanabe, Y.; Inaguma, Y.; Sato, H.; Miura-Fujiwara, E. A novel fabrication method for functionally graded materials under centrifugal force: The centrifugal mixed-powder method. Materials. 2009, 2, 2510-2525. [CrossRef]

28. Ocylok, S.; Alexeev, E.; Mann, S.; Weisheit, A.; Wissenbach, K.; Kelbassa, I. Correlations of melt pool geometry and process parameters during laser metal deposition by coaxial process monitoring. Phys. Procedia 2014, 56, 228-238. [CrossRef]

29. Karnati, S.; Axelsen, I.; Liou, F.F.; Newkirk, J.W. Investigation of Tensile Properties of Bulk and SLM Fabricated 304L Stainless Steel Using Various Gage Length Specimens. In Proceedings of the Proceedings of the 27th Solid Freeform Fabrication Symposium, Austin, TX, USA, 8-10 August 2016; pp. 592-604. 
30. Karnati, S.; Hoerchler, J.L.; Liou, F.; Newkirk, J.W. Influence of gage length on miniature tensile characterization of powder bed fabricated 304L stainless steel. In Proceedings of the 28th Solid Freeform Fabrication Symposium, Austin, TX, USA, 7-9 August 2017; pp. 289-306.

31. Zhang, Y.; Yan, L.; Liou, F. Improved initial guess with semi-subpixel level accuracy in digital image correlation by feature-based method. Opt. Lasers Eng. 2018, 104, 149-158. [CrossRef]

32. Cohen, A. Properties of cast copper alloys. ASM Handb. 1990, 2, 356-391.

33. Naeem, M. Laser processing of reflective materials. Laser Tech. J. 2013, 10, 18-20. [CrossRef]

34. Javidani, M.; Arreguin-Zavala, J.; Danovitch, J.; Tian, Y.; Brochu, M. Additive manufacturing of AlSi10Mg alloy using direct energy deposition: Microstructure and hardness characterization. J. Therm. Spray Technol. 2017, 26, 587-597. [CrossRef]

35. Adeyemi, A.A.; Akinlabi, E.; Mahamood, R.M.; Sanusi, K.O.; Pityana, S.; Tlotleng, M. Influence of laser power on microstructure of laser metal deposited 17-4 PH stainless steel. IOP Conf. Ser. Mater. Sci. Eng. 2017, 225, 012028. [CrossRef]

(C) 2019 by the authors. Licensee MDPI, Basel, Switzerland. This article is an open access article distributed under the terms and conditions of the Creative Commons Attribution (CC BY) license (http:/ / creativecommons.org/licenses/by/4.0/). 